\title{
La razón religiosa según Zubiri
}

\author{
En₹o Solari \\ ESCUELA DE DERECHO \\ UNIVERSIDAD CATÓLICA DEL NORTE
}

Tratándose de la religión, Xavier Zubiri piensa que la inteligencia racional es una cierta probación del sentido envuelto en la afirmación religiosa, vale decir, en el juicio (predicativo o antepredicativo) que recae sobre cualquiera clase de idea teísta. Si se adopta la terminología del autor, la razón religiosa consistiría en la búsqueda allende la aprehensión del fundamento del poder de lo real en la medida en que éste ha sido interpretado campalmente como una realidad absolutamente absoluta. Desde la perspectiva racional, así, las ideas de Dios y los sentidos religiosos campales constituirían esbozos que deben ser sometidos a una experiencia para aclarar su verdad profunda. La literatura sobre Zubiri se ha concentrado en este momento racional de la religión, haciendo de la razón el lugar 'natural' de las religiones ${ }^{1}$. A mi modo de ver, debe emprenderse otro camino, según el cual la religión se plasma ya en el campo real', de manera que en la razón no hace más que desarrollarse en profundidad y con independencia de la aprehensión. A continuación, reconstruiré tentativamente, siguiendo el hilo de la filosofía de la inteligencia de Zubiri, el desarrollo de la razón

1 Cf. D. Gracia, Voluntad de verdad. Para leer a Zubiri (Barcelona, Labor 1986), pp. 218 y 234; del mismo, «Religación y religión en Zubiri», en M. Frajó (ed.), Filosofía de la religión. Estudios y textos (Madrid, Trotta 1994), pp. 496-501; A. Pintor-Ramos, «Religación y 'prueba' de Dios en Zubiri», en Razón y Fe 218 (1988), pp. 328-329; del mismo, «Zubiri: una filosofía de la religión cristiana», en Salmanticensis 42 (1995), pp. 374-379 y 388-393; y J. L. CABRia, «La fundamentalidad del Dios accesible: el teísmo filosófico de Xavier Zubiri», en J. L. Cabria y J. SÁnchez-Gey (eds.), Dios en el pensamiento hispano del siglo XX (Salamanca, Sígueme 2002), pp. 159-169.

2 Cf. E. Solari, «El logos del teísmo según Zubiri», en Pensamiento. Revista de investigación e información filosófica. Vol. 65 (2009) 246, pp. 833-880. 
religiosa a partir de sus propias raíces, que son la religación y los sentidos teístas construidos en el campo.

\section{La búsqueda teísta}

La razón es ese modo intelectivo caracterizado por la búsqueda principial y canónica de lo real en profundidad. Justamente por la necesidad de ir desde el campo hacia el mundo, la razón es una marcha ya incoada en el movimiento del logos. Pero aunque incoada en el logos, la razón busca la realidad profunda de las cosas allende el campo, y esa tensión por dar con lo profundo hace de la razón una inagotable marcha transcampal. La razón puede ser verdadera o falsa, pero por ser búsqueda es una intelección constitutivamente abierta. Es una intelección en profundidad siempre provisional y corregible, nunca cerrada, definitiva ni menos indesmentible.

La búsqueda tiene su estructura precisa. La razón se topa con los sentidos religiosos. Halla ante sí todo un lenguaje teísta enormemente complejo y diferenciado. La diversidad de actos religiosos de habla es un dato para la intelección racional. Los sentidos religiosos ya se han constituido campalmente cuando la inteligencia se pone en marcha. Esto significa que el campo religioso es principio y canon para la razón. El campo es indispensable para poner en marcha la dinámica mundanal de la razón, aunque a la vez los contenidos campales sean perfectamente alterables a la luz del fundamento buscado. Con todo derecho se puede decir que «lo que la razón busca es 'probar' esos sentidos y evaluar su solidez a la luz del fundamento» ${ }^{3}$. La búsqueda religiosa consiste en eso: en probar el logos del teísmo. La razón transforma el contenido de ese logos en un principio y en un canon para la búsqueda de la realidad profunda de los dioses. Esta realidad profunda es la realidad esencial de Dios. Si Dios es la realidad absolutamente absoluta determinada por el logos y atestiguada por el lenguaje y la historia en toda su sorprendente diversidad, la inteligencia tiene aún una tarea por delante: la de determinar su razón definitiva.

La razón definitiva no es otra que ser fundamento en el fondo y en profundidad tanto del hombre como del mundo. El logos trata de determinar el fundamento puramente campal de lo dado primordialmente. La intelección propia del logos religioso es un movimiento intelectivo:

3 A. Pintor-Ramos, Realidady sentido. Desde una inspiración zubiriana (Salamanca, Ediciones de la U. P. de Salamanca 1993), p. 186. 
primero, va desde la impresión primaria de realidad hacia las ideas o simples aprehensiones que permiten determinar la figura de lo aprehendido, y segundo, vuelve desde esas ideas hasta lo aprehendido para afirmar lo que éste no simplemente sería sino lo que es en realidad entre otras cosas. Esta determinación campal de lo real es una aproximación al fundamento. Pero sólo una primera y todavía insuficiente aproximación. El campo religioso ha de ser transcendido. La transcendencia consiste en afinar la determinación del fundamento de lo aprehendido. Tal afinamiento es ya mundanal, y supone que el propio logos teísta ha de ser puesto a prueba a la luz de una razón que sobrepasa el campo. La realidad-fundamento es, primordialmente, la realidad en su fundamentalidad última, posibilitante e impelente, es decir, el poder de lo real. Fundamento es el carácter último, posibilitante e impelente de la realidad en cuya virtud ésta es poderosa. En segundo lugar, la realidad-fundamento es el conjunto casi inabarcable de sentidos teístas que se puede otorgar al poder de lo real en el campo y en función de las cosas incluidas en él. El logos es determinación del poder como realidad plenaria, y por ello es también afirmación de que el poder tiene un fundamento divino. Dios es, entonces, el fundamento campal del poder de lo real. Y en tercer lugar, debe decirse que la realidad-fundamento es la estructura profunda de la realidad plenaria afirmada por las ideas teístas. Es la búsqueda del fundamento mundanal de las divinidades campalmente determinadas. La razón se apoya en el logos religioso para buscar el sentido profundo, el fundamento inapelable, último y definitivo de sus afirmaciones, aunque jamás puedan sus resultados ser inapelables, últimos y definitivos. Si el logos procura un fundamento campal, entonces la razón pretende el fundamento mundanal, un fundamento que en el caso de Dios transciende incluso al mundo. La marcha intelectiva allende la aprehensión que pretende ser la razón busca la estructura esencial y definitiva de la realidad divina construida en el campo. Si esta realidad era el fundamento del poder, lo que busca postreramente la razón es el fundamento de dicho fundamento más allá del campo. La razón proyecta sobre el mundo el fundamento campal, lo convierte en esbozo y lo prueba para encontrar su realidad profunda. De ahí, dicho sea de paso, que sólo a la razón religiosa deban reclamarse las 'pruebas' o 'demostraciones' de la existencia de la divinidad.

Tenemos, pues, tres formas de considerar el fundamento, lo que permite apreciar la polisemia de esta noción. Una forma lo identifica con el poder de lo real, otra, con la determinación teísta del poder en el 
campo de la realidad, y otra, con la búsqueda abierta y corregible de una razón esencial (no sólo transcampal sino también transmundanal) para los diversos sentidos teístas. En este tercer caso, el fundamento ha de ser determinado sobre el telón de fondo del mundo, si bien el mismo mundo habrá de quedar superado por la esencia que se busca. Ya no se trata del mero horizonte campal en el que algo es determinado entre otras cosas y en función de ellas, sino que se trata de la totalidad de las cosas reales, esto es, del mundo en el que, y más allá del que, se busca la estructura profunda de Dios. ¿Qué quiere decir esto? La totalidad de lo real sigue siendo el lugar para determinar a Dios en profundidad. La razón religiosa es intellectus quaerens, y lo que busca es precisamente dar razón de lo divino sobre el telón de fondo del mundo. Sin embargo, el sentido mundanal de Dios tiene la particularidad de escapar del mundo. El logos es el ámbito del sentido, y la razón prueba el sentido del logos. Lo que no quiere decir que en el logos no haya pretensión de verdad, o que la razón sólo tenga valor de verdad y no incluya sentido alguno. En el logos hay que distinguir una autenticidad y una conformidad: es la verdad dual del logos. Y en la razón, si bien se sobrepasa el campo, no se abandona el orbe del sentido: es la búsqueda del sentido profundo del sentido campal. Para Zubiri, a mi modo de ver, el ser es el sentido del mundo. El sentido de cada cosa real reposa en el sentido global de lo real qua real. El mundo es el sentido de todos los sentidos; por ello, es la condición de posibilidad de cualquier sentido en particular. Y la búsqueda religiosa es una marcha que no sólo traspasa el ámbito campal sino que perfora la propia realidad mundanal. Lo que se busca es justamente el sentido en profundidad, allende el mundo aunque manifestado en él, de las ideas de Dios y, a fortiori, de las afirmaciones religiosas. Tal es el cometido de los esbozos, que son determinaciones mundanales de lo que los sentidos campales 'podrían ser'. El esbozo es el sentido que lo real campalmente aprehendido podría tener en el mundo. Si el esbozo religioso traspasa el ámbito mundanal y el ser es el sentido del mundo, entonces Dios no 'es' ni tiene sentido mundanal alguno. Su sentido es rigurosamente transmundanal. Este sentido, que es un unicum, es el que la razón busca, somete a prueba y verifica.

Mas, como todo sentido, el racional también es sentido de la realidad y a la vez sentido para el hombre. Es lo que debemos examinar a continuación. 


\section{La libre creación de los dioses}

Para Zubiri, la razón es mía y de las cosas: la razón es un modo ulterior de la intelección humana, y por otro lado son las cosas las que dan o no razón de sí mismas. La razón busca la razón de las cosas. Por ello, la razón de la religión es tanto una búsqueda emprendida como un fundamento buscado. La explicación es clara. Toda intelección actualiza de alguna manera a la realidad; es, en palabras de Zubiri, la congeneridad entre intelección y realidad. La actualidad mienta justamente esa unidad entre la intelección y lo inteligido, unidad formalmente 'noérgica' -dice Zubiri- en la que pueden distinguirse, como dos momentos intencionales, el polo noético y el polo noemático. En la razón también existe esa unidad noérgica de actualidad, aunque sin la compacción de la aprehensión primordial. Pero si bien no hay compacción, la intelección racional actualiza la realidad, y es por ende intrínseca unidad entre una marcha que busca allende el campo y aquello que se busca profundamente en el mundo. De esta forma, la búsqueda predetermina el orbe de lo buscado. La razón es mundanal, porque es marcha transcampal. Y el mundo es asunto de intelección racional, porque es el orbe de la estructura profunda de todas las cosas. Esto es lo que permite entender que la razón sea mía y de las cosas, y que se pueda decir que la razón es una intelección derivada y también que es lo inteligido en profundidad. La razón religiosa tiene esta misma característica. Es razón que busca lo divino, y es razón profunda de lo divino mismo. La actualidad racional, diría Zubiri, es la unidad noérgica entre una marcha en pos del fundamento de los lógoi teístas y ese mismo fundamento buscado en el mundo y que desborda al propio mundo. La razón es búsqueda profunda de Dios, y es a la vez la realidad divina en tanto que buscada en profundidad.

Pero hay más. La razón, mía y de las cosas, es libre. La intelección racional es una marcha libre que intenta determinar el contenido fundamental de lo real (en la tercera acepción de fundamento, por supuesto). Y la libertad de esta intelección deja su marca en el contenido inteligido de las cosas. Zubiri habla de tres tipos de libre creación racional: la experiencia o ensayo libre, la hipótesis, y la libre construcción o postulación. La razón cuestiona la estructura profunda de lo campalmente inteligido, de esas representaciones que son las simples aprehensiones y las afirmaciones. Entonces puede decirse que la razón religiosa investiga el contenido fundamental de las representaciones teístas. Estas mismas representaciones son el principio necesario de dicha investigación. Pero aunque se basa 
y apoya en la intelección campal, la razón no es meramente representativa sino que es una búsqueda de contenido fundamental allende el campo. La razón, dice Zubiri, 'dota' de contenido radical a lo campalmente aprehendido. Y la razón religiosa dota de contenido fundamental al teísmo. Esta dotación es la que es libre. La intelección racional de los sentidos religiosos campales también elabora unos sentidos, esta vez mundanales o, más bien, extramundanales. Dicha elaboración es una libre creación de contenido fundamental. La pregunta es si esta libertad es la de una experiencia o ensayo, la de una hipótesis o, todavía más, la de una construcción. ¿En qué consiste, precisamente, la libertad de la razón religiosa?

La respuesta es clara: dada la índole de la posible realidad de Dios, la libre creación de los dioses ha de ser constructiva. No es mera libertad para modelar notas o para homologar estructuras, sino que es máxima libertad para postular unas y otras. La libertad es libertad de construcción:

«Libertad es liberación de todo lo campal para construir el contenido de la realidad profunda. Esta realización libre no es producción, sino que es una realización tan sólo en la línea de la actualidad. Realización independiente del campo y sin producción: he aquí la libre construcción» ${ }^{4}$.

La libre construcción postula en la realidad un contenido fundamental liberado de la representación campal. Los ejemplos de Zubiri coinciden con los dados a propósito del logos; entonces eran las matemáticas y las ficciones novelescas, y ahora, el espacio geométrico, la estructura matemática de la naturaleza física y esa libre creación no teórica que es la novela ${ }^{5}$. Zubiri reconoce que ha hablado de la misma postulación en el logos y en la razón: «ya lo expliqué en la Segunda Parte» ${ }^{6}$. Podría decirse, pues, que la religión, arraigada como está en la religación, asoma recién en el logos cuando brota el sentido religioso, que es la postulación constructiva del sentido teísta en el campo real. Pero la religión se prolonga en la razón, que marcha allende el campo del logos tras el sentido más profundo de la divinidad, construyendo libremente su contenido fundamental tanto por lo que toca a sus notas como por lo que respecta a su sistematización. La religión es asunto del logos y de la razón, claro que de modo distinto. El

$4 \quad$ X. ZubIri, Inteligencia sentiente: Inteligencia y rarón (Madrid, Alianza 1983), p. 128.

5 «No la llamo ficción, porque en toda libre construcción, por ficticia que sea, entran no sólo fictos sino también perceptos, conceptos y afirmaciones»: X. ZUBIRI (n. 4), p. 129.

$6 \quad$ X. Zubiri (n. 4), p. 129. 
logos se atiene al campo, mientras que la razón lo transciende. El sentido construido en cada caso tiene distinto ámbito de validez. Esto no debe ser malentendido. Que el logos se atenga al campo no significa que sea una replicación de la aprehensión primordial. La realidad campal puede ser la realidad dada en los contenidos de la impresión, pero también puede estar apoyada en esa realidad de la impresión para incluir una postulación constructiva de sus contenidos. En el logos, en general, el momento reversivo que va de lo irreal (las simples aprehensiones) hasta lo que es en realidad (mediante una afirmación) admite la postulación, lo que sucede cuando los contenidos de la realidad campal son libremente construidos, sin por eso desbordar el campo. En la razón, también en general, la búsqueda de la profundidad de las cosas, que crea el contenido fundamental de la realidad campal, puede consistir también en una postulación, lo que ocurre cuando el contenido profundo de las representaciones campales es libremente construido, desbordando así el campo e internándose en el mundo para terminar superándolo y transcendiéndolo. Volviendo a la religión, puede apreciarse que el logos teísta organiza su contenido -los sentidos teístas- con libertad respecto de los contenidos impresivos, aunque apoyándose de todos modos en éstos. Y que la razón religiosa se apoya en el campo pero para superarlo necesaria y libremente: la realidad profunda que busca es la de los dioses, una realidad que en rigor no conoce unas notas campales que le puedan servir de modelo ni unas estructuras básicas campales que puedan ser homologadas, pues tanto el hecho del poder como la posibilidad de Dios no tienen igual en el campo y, aun manifestándose en el mundo, tampoco son comparables con objetos intramundanos ni con la realidad mundanal. En el logos y la razón se constituyen unos sentidos. En el logos religioso, el sentido teísta del poder de lo real en el campo; en la razón religiosa, el sentido profundo de la divinidad más allá del mundo aunque manifestado en él. El logos idea, afirma y se representa a Dios a partir de la religación: es el orto campal de la religión en la intelección dual y en el lenguaje. La razón marcha en busca de la profunda realidad de lo divino a partir de la representación de Dios: es el desarrollo mundanal o, mejor, transmundanal de la religión en la intelección dual y en la experiencia. Son dos momentos en la constitución del sentido religioso y dos modos estructuralmente vinculados de postular y construir libremente el contenido campal y fundamental de la divinidad. La misma religión tiene estos dos niveles, niveles que tienen una estructura unitaria: la de una sola intelección que se va modalizando. Y es que, pese 
a sus diferencias, logos y razón son intelecciones duales cuya raíz común es la aprehensión primordial. Por ello la razón, aunque transcendente al campo, sin embargo se apoya en él como en su principio y medida. Y el logos, sin dejar de moverse dentro del campo, lo recorre con mayor o menor libertad presintiendo su profundidad no sólo mundanal sino también extramundanal. Dios es realidad plenaria; por eso transciende el campo y el mundo. El mundo es la apertura campal sugerida por el mismo campo, y el campo es el mundo sentido: Dios se manifiesta transcendentemente tanto en el uno como en el otro.

Esta unidad de los modos intelectivos ulteriores también se aprecia cuando se repara en los caracteres de la libre creación racional. La razón busca lo que lo real podría ser, su 'elemento' son las posibilidades. La razón religiosa es búsqueda de lo que Dios podría ser. El sentido transcampal de lo divino es la posible realidad profunda que la razón busca a partir de los sentidos teístas campalmente postulados. Logos y razón son movimientos libres de la intelección, y cuentan por ello con distintos caminos para recorrer el campo y marchar hacia el mundo y, tratándose de Dios, más allá de él. La diferencia está en que, mientras el logos irrealiza el contenido y discierne afirmativamente una simple aprehensión entre otras, la razón es búsqueda de lo posible en tanto que posible. La posibilidad es el objeto formal de la actividad de la razón 7 . La razón busca una posibilidad real: lo que la realidad profunda de Dios podría ser, el posible carácter fundamental de la divinidad (y, no hay que olvidarlo, del poder de lo real, ya que Dios es fundamento de este poder). Mas, también debe hablarse en plural de posibilidades. La razón colige y desarrolla un conjunto de posibilidades, y por eso es 'ex-plicativa'. Esto significa que la razón religiosa colige a través de un sistema de posibilidades la realidad profunda de Dios. La explicación de las representaciones teístas campales echa mano de un conjunto de fundamentaciones que puedan dar razón de ellas. Para explicar, es preciso reunir intelectivamente esta multiplicidad de posibles fundamentos. Pero la marcha hacia el sistema de posibilidades tiene un preciso punto de arranque, que es el campo religioso. Desde él brotan las posibilidades como vías sugeridas para explicar la realidad divina en profundidad. Vale decir, la razón recibe del campo un sistema de sugerencias, que son las posibilidades en cuanto campalmente sentidas e incoadas. Tales sugerencias son los sentidos teístas campalmente representados. Dichos sentidos ideados y afirmados tienen su modalización

7 Cf. X. Zubiri (n. 4), p. 142. 
racional. Para la razón, en efecto, son principios de determinación del contenido fundamental que posiblemente le corresponda a la divinidad desde un punto de vista transcampal. Posibilidades colegidas y explicadas a partir de su incoación campal, las sugerencias hacen que la razón marche siempre y sólo de manera concreta. Es lo que Zubiri llama mentalidad. Mentalidad es la concreción del lanzamiento intelectivo, la intrínseca concreción de la razón. Sus raíces son campales, y se hallan en el principio canónico, esto es, en las concretas sugerencias que el campo ofrece a la razón. La razón religiosa, en particular, es también concreta, y como tal constituye siempre una mentalidad peculiar: la mentalidad religiosa. No se trata de la mentalidad religiosa de un semita a diferencia de la de un chino o un americano, porque cuando se dice eso se alude a unas cualidades de la intelección que, pendientes como son de las dimensiones de la vida humana, ha de estudiar la sociología del conocimiento. Una filosofía de la inteligencia, por el contrario, atiende a la intrínseca cualificación religiosa del lanzamiento intelectivo racional, dejando en suspenso aquellos factores dimensionales incrustados en la intelección pero distinguibles de ésa su línea de lanzamiento. Esta concreción es la que permite hablar de la mentalidad religiosa a diferencia de la mentalidad científica o poética. La mentalidad religiosa es el concreto lanzamiento intelectivo por el que se busca el fundamento de la realidad absolutamente absoluta. La búsqueda del sentido profundo de la divinidad es lo que cualifica a la mentalidad religiosa en tanto que razón concreta.

\section{El conocimiento religioso}

La razón es conocimiento, dice Zubiri, y conocer es buscar el fundamento de lo aprehendido. La búsqueda del fundamento de la manifestación campal y mundanal de la realidad plenaria es lo que especifica al conocimiento de Dios. Mientras el conocer en general busca la realidad-fundamento de lo actualizado en el campo, el conocimiento religioso busca la realidadfundamento del poder de lo real y de sus sentidos teístas campales. La mentalidad religiosa es por ello el conocimiento concreto de lo que Dios podría ser en el fondo. El conocimiento intenta explicar la realidad divina a partir de un sistema de posibilidades campalmente sugeridas. Dichas posibilidades son las vías precisas a través de las cuales se despliega la libre actividad del conocer, la libertad para crear y construir el contenido fundamental de la realidad absolutamente absoluta. Ahora bien: el conocimiento religioso tiene una estructura formal propia, como la tiene todo 
conocimiento. Según Zubiri, los momentos del conocer, si se deja aparte el problema de la verdad, son la objetualidad y el método, pudiéndose distinguir en este último todavía otros tres momentos: el sistema de referencia, el esbozo y la experiencia. ¿Cuál es el carácter de esta compleja estructura tratándose del conocimiento religioso?

\subsection{La realidad objetual de Dios}

'Ob-jectum' es la cosa real 'o-puesta' sobre el telón de fondo del mundo. Zubiri destaca este matiz cuando habla de objetualidad para no recaer en la noción habitual de objeto: objetual es la cosa en tanto que está opuesta, es decir, situada o proyectada sobre el fondo o fundamento mundanal. En latín, dice, podría hablarse de lo ob-positum (más que de lo ob-jectum), o también de lo ob-sens (construido a partir de lo prae-sens y lo ab-sens), en alemán podría admitirse la expresión Gegenseiend (aunque existe Gegenstand, que significa precisamente opuesto), etc. Pero más allá de las palabras, se trata de que la cosa real, transformada por sí misma (y no por un movimiento subjetivo) en objeto de conocimiento, lleva allende el campo hacia su posible fundamento en el mundo. Dice Zubiri que en la objetualidad hay un carácter categorial (el $o b$ ) y una positividad (un positum), es decir, un estar presente, sólo presente y en su presentarse mismo. Positivo, en este sentido, no es necesariamente ni sólo lo que 'está ahí', que eso sería un keímenon, un jectum. Hay realidades que están presentes y que no están ahí: una vida personal, un acontecimiento histórico, etc. Zubiri insiste en atender al estar presente, a la presentación misma. Lo positivo tampoco es forzosamente un hecho, aunque la aprehensión racional misma sí que lo sea; un hecho es un positum que por su propia índole es observable para cualquiera, mientras que positivo es lo que está presente aunque por su índole no sea observable para cualquiera.

Habiendo dicho esto, debemos preguntar si hay propiamente hablando un objeto religioso: ¿es Dios una cosa campal transformable en objeto real? La realidad divina no es la de una cosa entre otras. Desde esta perspectiva, Dios no es ni puede ser objeto. Pero Zubiri ha ampliado la significación de objeto, utilizando la expresión objetualidad para designar el ámbito mundanal en el que algo aparece como recortado (en la medida en que se lo puede recortar) contra el fondo de su propio fundamento. Desde esta otra perspectiva, Dios sí podría ser una realidad objetiva o, mejor, objetual. La realidad aprehendida en el campo como absolutamente absoluta queda puesta en dirección hacia el mundo y, así, queda como 
opuesta, resaltada sobre el ámbito de su propio fundamento. De ahí que la razón se vea forzada a precisar la figura esencial del fundamento campal, a determinar (hasta donde ello sea posible) la realidad profunda de Dios. Ésta es la única manera de admitir una legítima 'objetualización de Dios'. Sólo así se respeta su calidad de realidad-fundamento, y no se olvida la esencial diferencia entre realidad-objeto y realidad-fundamento. Dios no es identificado como una realidad que estuviera ahí, un keimenon o un jectum, que eso sería justamente una ilegítima objetivización de Dios. Dios es objetual sólo en tanto que está puesto, de una manera incomparable, sobre su propio fondo fundamental, fondo que -por irrespectivo- más que mundanal es extramundanal. Pero lo que así está puesto es una cosa real campal o, más bien, el fundamento de toda cosa en el campo de realidad. Dicho campo, asegura Zubiri, es un campo de libertad. La libertad campal, en el caso de la religación, es la apertura de posibles sentidos para el poder de lo real, unos religiosos, otros no. Considerando esto, debe preguntarse si la posible realidad divina es una realidad solamente positiva o además factual. La respuesta de Zubiri, me parece, es indudable. En primera instancia, intelectivamente hablando, Dios no es una realidad sino una posibilidad. Es una posible determinación campal del poder de lo real. Dios es la posibilidad de una realidad plenaria que, aunque exista verdaderamente, no es por su propia índole observable para cualquiera. Podrá Dios ser existente y verdadero, pero no tendrá jamás la inmediatez de lo aprehendido primordialmente. Lo que equivale a decir que Dios no es intuido directa o inmediatamente; si hay Dios, sólo aparecerá primordialmente como poder de lo real. Como posible sentido del poder de lo real, Dios no es ni puede ser un factum, una realidad observable para cualquiera. Es justamente esta posible positividad no factual de Dios lo que permite añadir que el teísta, el ateo y el agnóstico están en pie de igualdad ante el problema de Dios. Para el logos, pues, Dios es una posibilidad postulada en el campo para el poder de lo real que está dado en él, la posibilidad de un positum único e insólito: es la posible realidad absolutamente absoluta. Y para la razón, Dios es todavía algo más que una posible realidad positiva postulada campalmente para el poder de lo real: es el posible contenido fundamental, en la realidad profunda, de esa posible realidad absolutamente absoluta. La razón religiosa, como se ve, se mueve en un orbe de posibilidades de segundo grado. Si en el campo Dios está postulado como un posible sentido del poder de lo real dado primordialmente, en el mundo Dios está buscado en profundidad y por ello es un quaesitum. 
Lo que se busca no es su posible positividad campal sino el fundamento transcampal de ella, o sea, el posible contenido fundamental de la posible realidad absolutamente absoluta. La objetualidad es, pues, la constitución del ámbito del sentido transmundanal de Dios.

Nuevamente, no hay que malentender qué significa que la de Dios sea una realidad construida por postulación. Dios es una posibilidad: puede haber o no haber Dios. En este sentido previo, ante el hecho de distintas configuraciones campales y mundanales (unas religiosas y otras no) del poder de lo real, Dios es una posibilidad. Una posibilidad que fenomenológicamente no es descartable ni forzosa, al igual que las otras posibilidades. Esta pura posibilidad de Dios es la que es construida por postulación, tal como las posibilidades no teístas son también construidas por postulación. La libre construcción de Dios, de todos modos, no es equiparable a la de una realidad matemática o ficticia, cuyo contenido real postulado pende completamente del acto de postulación. Y es que, en el fondo, una sola de las posibilidades campales y fundamentales tendrá que 'ser el caso': o bien resulta que hay Dios, o que no lo hay. Para el logos filosófico, lo que hace la intelección dual es construir libremente posibilidades de determinación campal y transcampal del poder de lo real. Mas, como el poder de lo real tendrá que tener o no tener un fundamento divino, la libre construcción no es ni causa, ni raíz, ni fuente de esta realidad plenaria o de su inexistencia. Esta posible realidad plenaria de Dios no es una cosa aprehendida primordialmente, y no lo es porque no es una cosa entre otras y porque en la aprehensión primordial no se distingue a Dios sino sólo la dimensión transcendental del poder de lo real. Por eso la impresión de realidad sólo ofrece al análisis ese aspecto radical que es la religación de todas las cosas intramundanas, y que en el hombre toma la figura de voz de la consciencia. Sólo en el campo de la realidad la religación puede plasmarse religiosamente, y el poder, volverse una realidad absolutamente absoluta. La particularidad del modo intelectivo racional consiste en determinar mundanalmente a esta realidad plenaria. Pero tal particularidad de la razón no inhibe su unidad con el logos. El poder de lo real tiene en el campo una posición elusiva y una función fundamental. Tan fundamental que la realidad divina es justamente el fundamento campal del poder. La razón no hace más que marchar allende esta determinación campal del fundamento. El conocimiento religioso podrá decir entonces que el fundamento campal del poder, la realidad absolutamente absoluta, ha de tener a su vez un fundamento mundanal o, mejor, trans y 
extramundanal. En todo caso, no se trata de dos realidades distintas, sino de la misma realidad en dos niveles intelectivos diferentes. La manifestación campal entrega una primera determinación fundamental, mientras que la manifestación mundanal entrega la segunda determinación fundamental, la determinación definitiva aunque siempre abierta y provisional, pues la posible realidad de Dios sólo es vislumbrada por la intelección en una dirección propiamente infinita que nunca termina de recorrer. Sabemos que, campalmente, el poder reposa (en rigor, puede reposar) en la realidad absolutamente absoluta. Y que, más allá del campo, la realidad absolutamente absoluta está presente (en rigor, puede estar presente) sobre el telón de fondo del mundo y que por ello tiene que ser determinada desde el punto de vista de su realidad más profunda, en la limitadísima medida -claro- en que ello es posible.

Enseguida, hay que precisar en qué consiste esta determinación profunda de Dios. Es la única manera de llenar de contenido fundamental a la realidad divina, que hasta el momento no ha aparecido más que con su figura campal: la de la realidad plenaria, absolutamente absoluta.

\subsection{El método teísta}

La intelección marcha desde el objeto real hacia su fundamento en la realidad profunda. La manifestación mundanal de Dios plantea unas cuestiones que el logos no podía sospechar siquiera. Estas cuestiones no se identifican con un puro razonamiento, pues la razón, dice Zubiri, no es sinónimo de razonamiento. Aunque la razón es sistemática y hay un sistema de las verdades racionales, «el sistema de lo racional no es formalmente razonamiento» ${ }^{8}$. El logos juzga y razona, así como la razón también juzga y razona. El razonamiento es asunto de la lógica, mientras que el del método le incumbe a la fenomenología de la intelección. El método no es problema lógico, asegura Zubiri, sino 'noológico'. El método es el carácter de la marcha racional, es la vía de la razón. Por ello la razón es metódica. Si el método es la vía de la intelección desde el campo hacia el mundo, la razón religiosa es la que busca el posible fundamento de la realidad campal de Dios. La razón busca posibilidades para rellenar de contenido fundamental a la posible realidad de Dios, y el método no es más que el camino emprendido en dicha búsqueda. La razón tiene un problema: ¿cuál es el fundamento transcampal de esa posible realidad de

8 X. Zubiri (n. 4), p. 289 (vid. en gral. pp. 285-291). 
Dios de la que sólo se tiene representación campal? Y tiene también un modo de abordar este problema: es el método, la vía y el camino de la intelección que busca. Hemos de atender, a continuación, a los momentos de este camino.

\subsubsection{El sistema de referencia}

El primer momento de este camino, como no podía ser de otro modo, es la realidad campal o, mejor, el sentido campal de lo primordialmente aprehendido: es el sistema de referencia. Esto no debe ser identificado con el fundamento profundo y transcampal si la razón no quiere ser ingenua. Independientemente de que los contenidos campales y mundanales coincidan de hecho, el campo lanza a la intelección en dirección del fundamento de lo campal, más allá de las representaciones que hasta entonces se había formado. En el caso de la religión, se ha dicho que el sistema referencial es la religación?. Pero esto es equívoco. El sistema de referencia de la razón religiosa no es la religación en tanto que aprehendida primordialmente, sino el poder de lo real en tanto que a él se le da un particular sentido teísta. El logos determina al poder como fundado en la realidad absolutamente absoluta. Éste es precisamente el punto arranque de la razón religiosa. La razón toma a los sentidos teístas campales como el sistema de referencia de su marcha. Y, en principio, los particulares sistemas referenciales son algo que puede ser conservado o abolido. Las representaciones indican a la razón una vía para determinar en el mundo el posible contenido fundamental de lo aprehendido. Aunque las representaciones campales pueden ser verdaderas en cuanto tales, es posible que no lo sean en el nivel del mundo. Lo que es verdadero en el campo puede no serlo en el mundo. Así, habrá que ver si la realidad campal de Dios, no sólo absolutamente absoluta sino plenaria en algún sentido más particular y determinado, sigue siéndolo a la luz de la razón. ¿Qué quiere decir esto? Que tenemos que averiguar si la fundamentación campal del poder de lo real como una realidad plenaria concretamente determinada ha de ser conservada o no cuando se trata del fundamento de la divinidad en la profundidad del mundo.

El sistema de referencia, en efecto, adopta siempre unas figuras muy determinadas. Y las adopta porque el logos ha otorgado un sentido cam-

9 Cf. D. Gracia, Voluntad (n. 1), p. 222, y Religación (n. 1), p. 497; Pintor-Ramos, Religación (n. 1), p. 328; E. SOLARI, «La filosofía de la religión de Xavier Zubiri», en Revista Agustiniana 42 (2001), pp. 602 y 627; y Cabria (n. 1), p. 161. 
pal concreto al poder de lo real, pero sobre todo porque la razón religiosa no existe más que en unas configuraciones sumamente concretas. No me refiero a las dimensiones individuales, sociales e históricas de la razón, cuyo estudio pormenorizado escapa al análisis propio de la filosofía primera. Se trata de las diversas mentalidades religiosas, dentro de las cuales pueden distinguirse al menos las dos siguientes: la mentalidad del sentido común del creyente, y la mentalidad teológica propia del que adopta una determinada creencia religiosa reflexionando teorética y también confesionalmente acerca de ella. No religiosa, en cambio, es la mentalidad del que, aun adoptando una cierta creencia religiosa, no se sujeta confesionalmente a ella a la hora de pensarla sino que la pone entre paréntesis e intenta reflexionar acerca de la misma de manera teorética y además ecuménica y universal, sea que lo haga de una manera prevalentemente positiva, sea que lo haga de manera prevalentemente metafísica. Caben, por supuesto, sobreposiciones entre la mentalidad religiosa y la mentalidad no religiosa, en las que habrá que discernir si prevalece o no el vínculo de la sujeción confesional. Pues bien: en todas estas mentalidades es bien diversa la manera de apoyarse en el sistema referencial, y el tipo de lanzamiento intelectivo que aquel sistema provoca. Es cierto que las diferencias de mentalidad cualifican a todos y a cada uno de los momentos de la intelección racional. Pero el sistema referencial es un momento particularmente decisivo, justo porque la ingenuidad de la razón consiste en hacer de este sistema la estructura misma del mundo. Como veremos, la razón es la prueba de los sentidos teístas campalmente construidos, lo que implica que tales sentidos son referentes no constrictivos para la marcha racional en el mundo hacia el fundamento. Pero la prueba misma es diferente según sea la mentalidad de que se trate. Y las distintas mentalidades penden de las distintas maneras de apoyarse en el sistema de referencia y de ser lanzadas por éste. Es aquí donde se originan las mentalidades de un creyente, de un teólogo, de un científico y de un filósofo. Son mentalidades que se relacionan de maneras características con los lógoi religiosos.

Empero, antes de abordar estas mentalidades, notemos que hay un problema que sólo ahora podemos ponderar en toda su amplitud. Dios es la determinación campal del poder de lo real como una realidad absolutamente absoluta. ¿No sería más preciso hablar de una compleja serie de posibles representaciones religiosas en el campo de lo real? ¿Cómo se sabe que en todas ellas hay siempre una realidad absolutamente absoluta? Una respuesta es que si los dioses postulados por el logos no fuesen 
realidades plenarias, tendrían que estar sometidos a una instancia que sí es plenaria. Esto es lo que quizá hace Zubiri con las religiones aparentemente ateas, donde o no hay divinidad alguna, o si la hay es sólo una realidad suprahumana que no alcanza a ser absolutamente absoluta. En ambos casos, el carácter religioso de estas postulaciones radica en el reconocimiento de una instancia superior a la divinidad que es, ella sí, no solamente suprahumana sino estrictamente plenaria como realidad: por ejemplo una ley cosmo-moral, etc. De todos modos, ésta es una cuestión que ha de analizarse con mucho cuidado, viendo si el testimonio de la historia confirma que los sentidos religiosos conducen a una realidad absolutamente absoluta. El mismo Zubiri puede admitir que la posición anterior fuerza en demasía las cosas y que las llamadas religiones ateas en rigor no son religiones, pues no afirman con entera claridad una realidad plenaria. En cualquier caso, debe advertirse que estos sentidos religiosos, aunque siempre postularan una realidad plenaria, admiten una enorme diversidad y riqueza. Es toda la sorprendente variedad que exhibe el logos religioso. En él no se puede distinguir entre el sentido común, la ciencia, la teología y la filosofía, pues éstas ya son distinciones racionales. La diversidad de sentidos teístas no es una diversidad de mentalidades, sino una que sólo toca a las dimensiones individuales, sociales e históricas propias del logos. Sobre todo, aunque no exclusivamente, es la diversidad lingüística que cabe detectar en el campo de las religiones constituidas. Desde esta perspectiva, el lenguaje es el testigo par excellence de los numerosos y cambiantes sentidos teístas, y su análisis forma parte esencial de la filosofía de la religión.

Lo que nos interesa aquí son ante todo las mentalidades religiosas, que constituyen el asunto propio de la fenomenología de la intelección teísta, y no tanto las tres dimensiones de ésta, cuya investigación exhaustiva es propia de una psicología, de una sociología y de una historia de las religiones. Si nos referimos ahora a estas ciencias, no es desde un punto de vista interno o disciplinario. Aquí no se pretende una ciencia de la religión, sino algo distinto. El punto de vista es esencialmente externo, pues interesa describir lo más precisamente posible cómo se despliegan las mentalidades religiosas a partir de la determinación teísta del campo de realidad. Es el punto de vista de un análisis del surgimiento de las distintas mentalidades, de las diversas concreciones racionales de la intelección religiosa. En toda mentalidad hay un sistema de referencia, aunque en cada una este sistema adquiere diferente funcionalidad. Examinemos primero la mentalidad 
religiosa propia del sentido común. Este sentido común no es más que la intelección mediana, el ejercicio promedio, cotidiano de la inteligencia. El sentido común tiene, claro, momentos estructuralmente diversos, unos propios de la aprehensión primordial, otros del logos y otros ya racionales. Incluye, pues, las tres modalizaciones estructurales de la intelección, bien que con la figura concreta de la intelección de término medio. Justo por su estructura racionalmente modalizada, el sentido común es una mentalidad, puesto que constituye una concreción del lanzamiento intelectivo, y una concreción con su propio tipo, distinto por ejemplo del tipo de la ciencia ${ }^{10}$. Aunque desde cierta perspectiva el sentido común es más pobre que la ciencia, no es intrínsecamente un modo deficiente de ella. Son modos típicamente distintos de apoyatura en el campo para lanzarse problemáticamente hacia el fundamento en el mundo. Esto es lo que debe destacarse. El sentido común tiene su modo propio de reposar en la realidad campal para marchar hacia la realidad mundanal. Un modo que puede ser muy útil y apropiado para ciertos menesteres, y menos para otros. La ingenuidad de la razón, sin dejar de ser tal, tiene su propio rendimiento en la vida cotidiana. Como mentalidad, el sentido común es una reflexión

10 Aquí es preciso aclarar que no hay que identificar a la teoría con la mentalidad teorética. Para Zubiri, la razón procede siempre teóricamente, aun mediante el sentido común, lo que significa que ella es en esencia marcha transcampal en pos del fundamento; en cambio, la mentalidad teorética es un tipo particular de lanzamiento racional, el que está gobernado por un afán puramente especulativo o contemplativo, sin asomo casi de inclinación utilitaria o pragmática. Por esto la mentalidad del sentido común, sin ser teorética, es siempre una forma de teoría, de reflexión. De ahí que esta idea del sentido común no se identifique del todo con la del common sense de Reid, en la medida en que este autor parece excluir del ejercicio cotidiano de la inteligencia la posibilidad del examen racional de sus principios: «Si existen ciertos principios, tal y como yo sostengo, que la constitución de nuestra naturaleza nos lleva a creer y que nos vemos obligados a dar por hechos en la vida cotidiana, sin ser capaces de dar razón de ellos, éstos son los que llamamos los principios del sentido común; y lo que resulta manifiestamente contrario a estos principios es lo que llamamos absurdo»: Th. REID, Investigación sobre la mente humana según los principios del sentido común (trad. E. Duthie, Madrid, Trotta 2004), p. 92 (vid. también pp. 292-293). En cambio, la noción de actitud natural (natürliche Einstellung) de Husserl sí que parece incluir a la de mentalidad del sentido común, al menos porque admite explícitamente la posibilidad de la reflexión. Husserl, en efecto, acoge en la actitud natural la duda (Bezweiflung) e, incluso, el repudio (Verwerfung) y la borradura (herausstreichen) de ciertos datos o cosas particulares del mundo natural: vid. los $\iint$ 27-30 de Ideen, en E. HusserL, Ideen zu einer reinen Phänomenologie und phänomenologischen Philosopbie. Libro primero: Allgemeine Einführung in die reine Phänomenologie, en W. BIEMEL (ed.), Husserliana. Vol. 3/1 (Den Haag, Martinus Nijhoff 1950), pp. 56-63, esp. 61. 
que tiende a identificar al sistema referencial con la estructura mundanal. Abandonado a su propio movimiento, la reflexividad del sentido común suele afincarse en los sentidos teístas campalmente representados. Entonces la realidad absolutamente absoluta, que es la mínima determinación de Dios, resulta suficiente para la intelección racional. Esta realidad campal de lo divino, que sólo dice que es algo superior a todas las cosas intramundanas e incluso a la más excelente de ellas, al hombre, es a la vez todo el fundamento de Dios en la realidad profunda. A esta reflexión que identifica lo campal con lo mundanal pudiéramos llamarla la forma 'caída' del sentido común. Pero esto no es forzosamente así. La mentalidad del sentido común puede poner en entredicho esta identificación. La intelección promedio también se hace preguntas, y cuestiona sus propias ideas y juicios. El sentido común constituye una mentalidad predominantemente estereotipada y reflexivamente floja, pero en él puede asomar la preocupación teorética, la reflexión original no debida más que a un gesto de libertad intelectiva. Dicha preocupación manifiesta una posibilidad de reflexión no ingenua sino creativa y enérgica que brota del mismo sentido común. El afán especulativo no abole el sentido común sino -cosa distinta- la tendencia ingenua de la mentalidad del sentido común. Así, puede llegar a vislumbrar la insuficiencia reflexiva de la determinación campal de la realidad de Dios, aun cuando la acepte como correcta. Por eso es capaz incluso de admitir y promover la crítica de las representaciones usuales de la realidad divina. Por eso puede decirse, resumiendo, que la mentalidad del sentido común consiste en una reflexión tendencialmente repetitiva e ingenua, en la medida en que identifica a la realidad campal de Dios con su contenido fundamental, pero a condición de añadir que tiene la posibilidad crítica de no contentarse con ello y columbrar (reflexivamente también) la diferencia entre campo y mundo, es decir, entre la realidad absolutamente absoluta y los contenidos fundamentales que ella ha de tener o no tener. Esto muestra que la mentalidad religiosa del sentido común, aunque sólo fuera en casos contados y momentos excepcionales, puede no estar tan lejos de la mentalidad teorética.

La del teólogo es otro tipo de mentalidad. Tiene la peculiaridad de ser religiosa y a la vez intrínsecamente teorética. Si la religiosidad del sentido común es una mentalidad religiosa pragmática y tendencialmente ingenua, el teólogo tiene una mentalidad siempre y en todo caso religiosa y teorética. La mentalidad teológica, como la religiosa del sentido común, es una mentalidad asentada en una creencia religiosa peculiar. Para ambas menta- 
lidades, los sentidos teístas en los que se apoya la razón religiosa para buscar el fundamento mundanal de la realidad divina son unos sentidos aceptados y creídos. Frente a ello, lo que especifica a la mentalidad teológica es que esos sentidos teístas son sometidos a examen racional organizado y sistemático. El sistema de referencia, sin dejar nunca de ser aceptado y creído, es objeto de investigación. La mentalidad del teólogo se da perfecta cuenta de la diferencia entre campo y mundo, entre los sentidos teístas de una cierta religión y los problemas racionales de fundamentación envueltos en ellos. Justamente por esa necesidad de ir desde el campo hacia el mundo es que la teología se caracteriza por la sistemática búsqueda racional de fundamentos para esas representaciones que ha aceptado y en las que ha creído. Es lo que distingue a esta mentalidad de la mentalidad del sentido común, que suele descansar en la aceptación y la creencia de las representaciones campales. Y aunque el sentido común pueda escapar a la ingenuidad pragmática y preguntarse por el fundamento de sus ideas y afirmaciones acerca de Dios, tal posibilidad nunca es llevada a cabo de manera sistemática y continuada. En el fondo, es la diferencia que media entre una mentalidad religiosa no científica y otra que sí lo es. La mentalidad teológica ha de someter a permanente cuestionamiento el campo de sus representaciones teístas. Incluso las representaciones de otras religiones pueden ser parte de su propio sistema de referencia, ya no como unas representaciones aceptadas y creídas sino sólo como unas mejor o peor empleadas y conocidas. En este caso, la mentalidad teológica intenta precisar el lugar en el que se pueden ubicar las representaciones de otras religiones desde el punto de vista inconmoviblemente central que ocupan las de la propia religión. Esto muestra que el sistema de referencia de la mentalidad teológica puede ser más o menos rico en representaciones religiosas, aunque -como es obvio- posee mayor amplitud, complejidad y articulación que el sistema referencial del sentido común.

Tanto la mentalidad religiosa del sentido común como la mentalidad teológica son la materia principal de nuestro análisis. Éste es, en el lenguaje de Zubiri, un logos que, después de haber estudiado el logos específicamente religioso, se aboca a la explanación de la razón y la mentalidad religiosas. El análisis de la religión, pues, comienza con un dato prerreligioso, la aprehensión primordial del poder de lo real, y continúa con sus plasmaciones ulteriores, primero en el campo de los sentidos teístas y, después, a través de las concretas búsquedas en la realidad profunda de sus fundamentos racionales. Con todo, podemos añadir unas rápidas 
consideraciones analíticas acerca de las mentalidades teoréticas no religiosas cuyo objeto de estudio es la religión. En las mentalidades teoréticas no religiosas se advierte que el sistema de referencia posee una amplitud normalmente mayor que la que tiene en la razón religiosa. Digo mayor porque, como se ha destacado, la actualización campal del poder de lo real es determinada mediante los sentidos teístas, y las mentalidades teoréticas no religiosas intentan estudiar dichos sentidos teístas sin excluir en principio a ninguno, es decir, recogen (hasta donde es posible) el conjunto de todos ellos, sin restringirse a algunos en particular o de manera central. La mentalidad teorética no religiosa estudia tanto los lógoi teístas como las razones dadas acerca de las religiones, sin excluir a ninguno de ellos, y sin excluir tampoco la posibilidad de juzgar acerca de su consistencia e incluso de su grado de verdad. Así, las distintas formas de teoría científica o metafísica de la religión estudian no sólo la variedad fastuosa que ofrece el campo del teísmo, sino también los muchos ensayos racionales de determinación de los fundamentos mundanales de aquellos sentidos. Su tema, podría decirse también, es la investigación profunda de la realidad absolutamente absoluta a partir de toda la diversidad y mutabilidad de sus representaciones campales.

Pero no hay que perder de vista que, trate de la mentalidad religiosa o no religiosa, éste es un mero análisis. Las mentalidades son, en efecto, formas de teoría y no de análisis, concretas explicaciones racionales, no meras descripciones. Esto significa que, antes de toda teoría y para que pueda haberla, es preciso un estudio puramente analítico y descriptivo del fenómeno religioso. La analítica religiosa es estructuralmente anterior a la explicación religiosa. El momento teórico está intelectivamente montado en el analítico, sea o no la razón consciente de ello y aunque (como es casi inevitable) el análisis esté unido a alguna teoría. La mentalidad teorética no sólo admite sino que está ella misma basada en un modo anterior de intelección. Tratándose de la intelección religiosa, ese modo anterior es un puro análisis de la marcha desde el sistema de referencia hacia su fundamento en el mundo. Y el análisis es todavía logos: es justamente el logos acerca del despliegue racional del logos religioso. Como tal, es rigurosamente distinto de las mentalidades teoréticas, formas derivadas que ya estudian racionalmente a la razón religiosa. La fenomenología de Zubiri es logos y no razón acerca de la religión. El logos es un nivel intelectivo anterior a la razón, es decir, a todas las formas de la teoría, tanto las mentalidades religiosas (del sentido común y teológicas) como las menta- 
lidades teoréticas no religiosas encarnadas en las ciencias de las religiones y en las filosofías de la religión o, dicho más precisamente, en las teorías científicas y en las teorías metafísicas de la religión. La pretensión fenomenológica de Zubiri lo lleva a sostener que el logos también puede volcarse sobre las teorías medianas, teológicas, científicas y metafísicas que intentan explicar en profundidad los sentidos religiosos. El logos puede hacer de la teoría materia de análisis. De manera que la fenomenología de la religión incluye, aunque a primera vista parezca difícil o incluso imposible, un análisis de las explicaciones teístas. Y es que el logos puede estudiar ese modo intelectivo que es la razón.

\subsubsection{El esbozo}

Las mentalidades religiosas, con toda su diversidad, se apoyan en el sistema de referencia, y desde él emprenden una marcha siguiendo alguna dirección. La razón es, de esta manera, concreta reflexión sobre el logos que marcha allende el campo real. A partir del sistema referencial, aceptando o no sus sugerencias, la razón elabora lo que la realidad campal podría ser. Tal es el esbozo, el siguiente paso del método de la razón. Todo esbozo es marcha dirigida de alguna manera por el sistema referencial, y los esbozos religiosos no son la excepción. La razón marcha dirigida por los sentidos teístas otorgados al poder de lo real. Este sistema de referencia entrega posibilidades para inteligir en profundidad la posible realidad absolutamente absoluta de Dios. Sabemos que la dirección de la marcha está sugerida por el campo. Pero como tal sugerencia está sólo incoada, la marcha se despliega libremente. De ahí que, siendo el esbozo una libre construcción de posibilidades de fundamentación, la razón religiosa sea una búsqueda que opera por libre construcción del contenido fundamental de la realidad divina. Esta libertad para postular las notas y la estructura de Dios es la que conduce a elaborar posibilidades de fundamentación mundanal (en el entendido, repitámoslo, de que Dios es realidad fundamentalmente extramundanal). Sabemos que las posibilidades son reales e intelectivas a una; se esbozan los fundamentos de las cosas y las posibilidades de conocerlas. En tanto que reales, son los posibles contenidos fundamentales de la divinidad, y en tanto que intelectivas, constituyen a la vez posibilidades de conocer racionalmente a Dios. Y aunque suene a paradoja, es justo la limitación de las posibilidades la responsable de la apertura del conocimiento de Dios. La razón es abierta porque está intrínsecamente limitada: limitadas son las posibilidades que le sugiere 
el campo, y limitadas son las posibilidades de fundamentación a las que está lanzada y dirigida. El esbozo religioso tiene un margen de libertad y apertura para fundamentar la realidad absolutamente absoluta, margen en el cual tienen su peso propio las peculiaridades individuales, sociales e históricas de la propia razón humana. Tan importante es esto que Zubiri distingue los esbozos teístas tomando como criterio los diferentes niveles de las culturas que los elaboran: así, dice, hay dioses de los hombres prehistóricos, de las civilizaciones primitivas, de las civilizaciones primarias, de las secundarias y de las terciarias. En esta distinción se aprecia que los esbozos de Dios penden de la situación, de los cuerpos sociales y de sus formas de vida ${ }^{11}$.

Pero más allá de las diferencias atribuibles a la cultura y a la sociedad, el margen de los esbozos religiosos es intrínsecamente limitado y abierto y, por eso, casi inagotable. Los esbozos tienen formas extraordinariamente diversas. En cierta forma, cada religión es un esbozo de Dios. ¿Cómo abordar esta gigantesca diversidad? Zubiri enumera hasta quince manifestaciones de la realidad divina. En cada una de ellas hay no solamente una cierta idea de la divinidad, sino a la vez un ensayo de búsqueda racional de su realidad más profunda. También puede decirse que las tres orientaciones básicas de plasmación teísta de la religación (la politeísta de la dispersión, la panteísta de la inmanencia y la monoteísta de la transcendencia única y personal), si bien tienen su origen en el logos, sólo encuentran una posible fundamentación profunda en la razón. Además, los esbozos también son diversos porque la mentalidad que los elabora es en cada caso distinta. Las representaciones campales buscan su propia fundamentación siguiendo una particular trayectoria racional. De esta guisa, unos son los esbozos de la mentalidad religiosa del sentido común, y otros los de la mentalidad religiosa y teorética de la teología. Incluso la ciencia y la misma filosofía, cuando coinciden con la mentalidad religiosa, dan lugar a una serie de peculiares esbozos de Dios. Entre ellos, ocupan una posición privilegiada las tradicionales pruebas de la existencia de Dios, que no son más que esbozos teoréticos metafísicos o científicos acerca del contenido fundamental de Dios.

Mas, debe reconocerse que hablar del contenido fundamental de Dios es hablar de una manera bastante imprecisa. Y lo es porque incluye cues-

11 Cf. X. Zubiri, El problema filosófico de la bistoria de las religiones (Madrid, Alianza 1993), pp. 116-119. 
tiones tan varias como las vinculadas con la coherencia de las propiedades envueltas en la idea de Dios, con la existencia de la realidad divina, y con la pertinencia y significatividad del lenguaje empleado para hablar de ella. Estas diversas cuestiones, en las que tanto ha insistido la filosofía analítica, permiten advertir un rasgo esencial de la mentalidad religiosa, sea del sentido común o teológica, e incluso científica y filosófica (cuando coinciden con aquélla). La razón es siempre reflexiva, pues consiste en una vuelta sobre el logos. El logos es apoyo y punto de partida para la razón, y por ello entrega las sugerencias que dirigen (claro que libremente) la marcha racional. En el logos se hallan nombres y afirmaciones teístas, así como diversas ideas acerca de las notas y la estructura de Dios, e incluso una afirmación puramente campal (y meramente conativa) de su existencia. La razón, por su esencial referencia al logos, ha de ser por lo tanto reflexión acerca del lenguaje religioso, reflexión acerca de la coherencia de las representaciones de Dios, y reflexión acerca de la existencia del Dios representado de tal o cual manera. Hay que admitir que es difícil encontrar un mínimo común denominador para todas estas reflexiones. Por ejemplo, la reflexión acerca de la idea de Dios puede entregar resultados enormemente divergentes, aunque todos ellos se asienten en la idea de una realidad absolutamente absoluta. Zubiri aventura que en todo esbozo religioso se toma como sistema de referencia, en la forma que sea, a la realidad absolutamente absoluta, a la divinidad. Es la analogía no sólo del absoluto sino de la realidad, la oscilación entre la relatividad universal (absoluta en el hombre, relativa en las demás cosas) y la absoluta absolutez divina. El esbozo ha de ser por fuerza, apoyado como está en el campo, una determinada fundamentación de esta analogía de la realidad. Es el intento de dar base profunda a la realidad absolutamente absoluta y esencialmente transcendente. Lo que especifica a todo esbozo teísta no es más que la búsqueda de lo que Dios podría ser en el fondo, y su resultado (recordemos: siempre provisional y corregible) son unos rasgos profundos postulados por la mentalidad religiosa para la realidad absolutamente absoluta. Si el poder de lo real es lo más próximo y lo más lejano, y si Dios es el sentido campal del poder, entonces su realidad plenaria tiene que ser esencialmente fontanal y completamente otra, como de hecho parece acreditar una y otra vez la historia de las religiones. Desde esta perspectiva, la realidad de Dios no es sólo otra en la aprehensión humana, ni siquiera es sólo independiente de ésta, sino que es en todas las manifestaciones de la razón religiosa la realidad otra e independiente par excellence, otra en re- 
lación con el campo y, transcampalmente, otra también en relación con el mundo. He aquí que la alteridad de Dios no se limita a su diferencia campal, sino que remonta sobre ella definiéndose como diferencia respecto del mundo independientemente de la aprehensión. La razón, que tiene numerosas posibilidades de fundamentar a la realidad divina, sin embargo ha de respetar escrupulosamente su constitutiva e insuperable alteridad. Por mucho que se pueda decir de Dios, esta realidad permanece inaccesible, innombrable, inenjuiciable, allende las posibilidades fundamentadoras de la razón. Dios es otro con respecto a todas las cosas y, en particular, por lo que toca a cada uno de los modos intelectivos. Pero la determinabilidad racional del totalmente otro, del que transciende su propia manifestación campal, sin embargo se apoya en tal manifestación misteriosa y excesiva, y de ella procede. Entonces, arrancando del campo, el esbozo teísta es la precisión transcampal de Dios, esto es, de la realidad plenaria y transcendente que está más allá del ser. Y es que Dios funge de sostén universal, raíz donante de posibilidades e impulsor de la realidad humana. Dios es el totalmente otro y, a la vez, el máximamente próximo. Las paradojas del logos no cesan con la razón, sino que son sometidas a profundización y a probación física. La razón tampoco entiende que la absoluta alteridad de Dios sea compatible con la más absoluta cercanía. Si lo sagrado es mysterium tremendum et fascinans, habrá que añadir de inmediato que lo es porque Dios mismo es paradójicamente la suma realidad atrayente y horrorizante. Estos rasgos del poder de lo real, la cercanía máxima y simultáneamente la mayor lejanía, son las dos caras de la transcendencia divina. Dios es transcendente porque es a la vez el totalmente otro y la intimidad más íntima. Por eso es independiente del mundo real en su totalidad, y en este sentido es rigurosamente extramundano, pero lo es en la misma medida que está en el fondo de todas las cosas intramundanas y del hombre en particular, como la realidad última, posibilitante e impelente, o sea, como sostén, raíz e impulso. En breve, los esbozos teístas tienen un mismo sistema de referencia en la medida que en toda la gama de los sentidos religiosos campales se habla de Dios, aunque de maneras bien diversas. La marcha racional que pretende determinar en el fondo la realidad de Dios absolutamente absoluta y transcendente, fontanalis, totalmente otra y totalmente cercana: esto es, según Zubiri, lo que hay en común en todos los esbozos acerca del sentido profundo de Dios.

Pero a partir de la transcendencia fontanal de Dios, las posibles fundamentaciones son muchas. Todas ellas son posibilidades de fundamenta- 
ción de la realidad absolutamente otra y próxima. Algunas vías racionales llevan al esbozo de Dios como una realidad única, personal y transcendente. Otras llevan a esbozar a Dios como realidad múltiple, o apersonal, o incluso inmanente. Sabemos que ya en el logos cabe reconocer al menos tres orientaciones teístas, caracterizadas por el dominio de una idea dispersa, inmanente o personalmente transcendente de Dios. Conforme a estas tres grandes orientaciones teístas, Zubiri suele distinguir tres vías de la razón religiosa: la politeísta, la panteísta y la monoteísta. El politeísmo es la vía de la dispersión del poder de lo real y de la realidad absolutamente absoluta en una pluralidad de divinidades sustantivas: «[...] la vía del 'hacia' en sentido de la dispersión [...], la distribución o dispersión el poder de la deidad en varias cosas $\rangle^{12}$. Tales divinidades suelen constituir un sistema complejo, un panteón funcionalmente organizado de dioses. En este cuerpo absolutamente transcendente de divinidades, dice Zubiri, siempre hay un Dios supremo, uno al que se dirige el ser humano «como si fuese el único», pues en él se refleja todo el panteón divino: es el fenómeno del henoteísmo atestiguado, entre otras religiones, por la religión védica y por la babilónica ${ }^{13}$. El panteísmo es la vía de la inmanencia del poder de lo real y de la realidad absolutamente absoluta en la totalidad del cosmos: entonces, sin perder su transcendencia fontanal, Dios está adscrito a la estructura toda de la realidad. Incluso si hay varias divinidades, o ninguna en absoluto, el conjunto del universo está sometido al conjunto de los dioses, o a uno solo de ellos, o por último a una legalidad superior a todos ellos que sí es absolutamente absoluta. Hay variados ejemplos de panteísmo, como el brahmánico -para el que «todo tiene una subsistencia divina»» ${ }^{14}$, la religión cósmica de los estoicos y los diversos panteísmos concebidos en Europa ${ }^{15}$. Cuando se dice que ciertas religiones ateas pudieran ser consideradas como teísmos por admitir eventualmente una ley inmanente al cosmos que es absolutamente absoluta - «en estas religiones existe la divinización de la Ley misma del cosmos» ${ }^{16}-$, lo que se dice en el fondo es que quizá sean religiones panteístas. En todos los panteísmos la divinidad se identifica, en algún sentido, con el universo entero: se «atribuye al

\footnotetext{
X. Zubiri (n. 11), pp. 137 y 151.

X. Zubiri (n. 11), pp. 137-138.

4 X. Zubiri (n. 11), p. 323.

15 X. Zubiri (n. 11), pp. 139 y 151.

16 X. Zubiri (n. 11), p. 139.
} 
mundo las propiedades de Dios o a Dios las propiedades del mundo» ${ }^{17}$. El monoteísmo es la vía de la transcendencia del poder de lo real y de la realidad absolutamente absoluta en una sola y única divinidad personal. No hay que confundir la transcendencia de la divinidad con la interpretación monoteísta de la misma. Aquélla no es más que el momento básico de todo esbozo teísta, en cuya virtud Dios es absolutamente otro y absolutamente fontanal. Ésta, en cambio, es un esbozo de la realidad plenaria como 'única, personal y transcendente', al decir de Zubiri. Quizá fuera mejor decir que el monoteísmo es el esbozo de la unicidad personal de la transcendencia divina. La transcendencia fontanal de la realidad absolutamente absoluta es concentrada, mediante un lenguaje más o menos antropomórfico, en la persona única de Dios. Su historia es también muy compleja: allí están la religión de Zaratustra, la de Israel, el cristianismo y el Islam ${ }^{18}$. Hay, pues, cuando menos, unos esbozos racionales de Dios que siguen unas vías politeístas, otros unas vías panteístas y otros unas vías monoteístas. Estas tres gruesas agrupaciones no empecen a la posibilidad de hacer distinciones más sutiles, por supuesto. Pero tal vez todas las ideas de Dios, con sus matices y peculiaridades, puedan ser referidas a estos tres grupos genéricos. Zubiri, por ejemplo, se enfrenta con el fenómeno de las religiones dualistas, sea ubicándolo en el monoteísmo, sea en el politeísmo ${ }^{19}$.

Sabemos que hay un mismo sistema de referencia para todo esbozo teísta: es, como muestra el análisis filosófico del logos teísta, la admisión de una realidad absolutamente absoluta, realidad plenaria que es el sentido de Dios que cualquiera entiende y que brota de la entera historia religiosa del ser humano. Mas, aunque todo esbozo racional se asienta en este mismo sistema de referencia, que es la determinación campal del poder

17 X. Zubiri (n. 11), pp. 143-144.

18 X. Zubiri (n. 11), pp. 139-142 y 151; del mismo, Sobre el sentimiento y la volición (Madrid, Alianza 1992), pp. 282-283.

19 En el curso de 1964 sobre el problema del mal, Zubiri realizó una breve historia del dualismo religioso y filosófico; vid. X. Zubiri, Sentimiento (n. 18), pp. 197-198 y 238245. Su conclusión es que en estos dualismos el mal es un momento sustantivo, sea este momento una sustancia, como en el maniqueísmo, el mazdeísmo y el zurvanismo, sea un principio sustancial, como en Grecia y en el neoplatonismo. Cf. también X. Zubiri, «Zurvanismo», en Gran Enciclopedia del Mundo Vol. 19 (Bilbao, Durvan 1964), pp. 485-486; del mismo (n. 11), p. 141; del mismo, Estructura dinámica de la realidad (Madrid, Alianza 1989), p. 284; del mismo, Espacio. Tiempo. Materia (Madrid, Alianza 1996), pp. 220-221. 
de lo real como realidad plenaria, tal referencia de la razón tiene en cada caso un sentido, una significación peculiar y concreta. La posible realidad divina tiene diversas y cambiantes figuras campales. Pero también por su contenido propio, el esbozo de la razón puede conducir a muy distintas determinaciones fundamentales, cosa que también atestigua profusamente la historia de las religiones. Por esto puede haber una discrepancia entre el sistema referencial y el esbozo de la razón, esbozo que puede aumentar, disminuir o simplemente transformar los concretos caracteres campales de la divinidad, de la realidad absolutamente absoluta. Todavía más: puede haber una enorme diferencia entre los mismos esbozos teístas según las líneas que siga la razón. Y esta otra fuente de discrepancias, a su vez, admite también que los esbozos sean diversos por distintos motivos. No son diversos sólo porque diversas son las vías religiosas: unas panteístas, otras politeístas y otras monoteístas. Es que, a veces, el esbozo racional que hacen las religiones no se ajusta al que llevan a cabo los filósofos. Con mayor precisión, debiera decirse que en el mismo terreno religioso se aprecia con frecuencia un vaivén entre la mentalidad teorética de la filosofía y la mentalidad del sentido común. Por eso, siguiendo la fórmula inspirada en Pascal, tenemos que preguntar si para Zubiri el Dios de los filósofos es el mismo Dios de las religiones. He aquí, me parece, el texto decisivo para responder:

«Sólo es Dios en tanto que Dios aquella realidad que es absolutamente última, fuente de todas las posibilidades que tiene el hombre para vivir, y en quien se apoya para tener que ser. Ninguno de estos momentos aisladamente considerados constituye lo que todos entendemos por Dios y lo que este vocablo significa en la historia entera de las religiones. Por esto es por lo que el Theós de Aristóteles no es propiamente hablando Dios. Se pensará entonces en la célebre distinción de Pascal entre el Dios de los filósofos y el Dios de las religiones. Alguna razón tiene pero sólo alguna. Primero, porque hubiera hecho falta que nos dijera en qué consiste el Dios de las religiones; y no nos lo dice. Segundo, porque el Dios de las religiones es el Dios a que filosóficamente se llega siempre que la filosofía no se acantone en nociones griegas. La vía de la religación ha llegado filosóficamente a una realidad absolutamente absoluta que es realidad última, posibilitante e impelente, esto es, al Dios de las religiones en tanto que Dios $»^{20}$.

Ha de recordarse qué es lo que decía Pascal exactamente. En «El Memorial», el famoso fragmento del 23 de noviembre de 1654, habla del

20 X. Zubiri, El hombre y Dios (Madrid, Alianza 1984), pp. 151-152. 
«Dios de Abraham, Dios de Isaac, Dios de Jacob, no de los filósofos y de los sabios» ${ }^{21}$. Éste es «el Dios de los cristianos» $»^{22}$. A un Dios tal, claro, no se le conoce «más que por Jesucristo» ${ }^{23}$. Con todo, Pascal no refuta completamente a la razón, y admite por ejemplo la validez lógica de las pruebas metafísicas de la existencia de Dios. Y sin embargo, en su opinión dichas pruebas muestran que el rendimiento cognoscitivo de la curiosidad es arruinado por la soberbia (como dice Agustín en el Sermo 141,2), que no sería más que la pretensión de conocer a Dios sin Jesucristo ${ }^{24}$. Por eso en «Infinitamente nada (Infini rien)», fragmento designado corrientemente como «La apuesta (Le pari)», Pascal agrega:

«Es el corazón el que siente a Dios, y no la razón: he aquí lo que es la fe. Dios sensible al corazón, no a la razón. El corazón tiene sus razones que la razón no conoce: se lo sabe en mil cosas $»^{25}$.

Pues bien: si prescindimos de la concentración en el Dios cristiano del argumento de Pascal y lo ampliamos de manera que incluya no solamente al cristianismo sino a las demás religiones, podemos decir que Zubiri parece sensible a este argumento, porque admite que la mentalidad teorética de la filosofía frecuentemente distorsiona al Dios de la mentalidad del sentido común. En el texto antes citado, Zubiri asegura que el Dios aristotélico no es Dios porque sólo es último, no posibilitante ni impelente. A la vez, dice que es posible dirigirse racionalmente al Dios de las religiones siempre que la inteligencia no se limite a las posibilidades que arrancan de la filosofía griega. Por esto asevera que «la religión no es lo mismo que la metafísica $\rangle^{26}$, y que el monoteísmo religioso no es lo mismo que uno «meramente metafísico» ${ }^{27}$. Puede notarse también la semejanza del siguiente pasaje de Zubiri con las conocidas expresiones de Heidegger en La constitución onto-teo-lógica de la metafísica, que versan ambos en torno a la causa prima:

21 B. Pascal, Les Provinciales, Pensées et opuscules divers (Paris, Le Livre de Poche 2004), p. 1300.

22 B. Pascal (n. 21), pp. 1235-1236.

23 B. PASCAL (n. 21), p. 936.

24 Cf. B. Pascal (n. 21), p. 937.

25 B. Pascal (n. 21), p. 1217. Y una fe, conviene añadir, que es don de la gracia y no del esfuerzo natural del hombre: se está unido a Dios «por gracia, no por naturaleza»: B. Pascal (n. 21), p. 921.

26 X. Zubiri (n. 11), p. 140.

27 X. Zubiri (n. 11), p. 166. 
«La causa primera, ¿es aquello que los hombres llaman Dios, eso a que el hombre se dirige no sólo con la demostración, sino con todos los actos de sumisión, plegaria, etc.? Dicho un poco externamente, esa causa primera, ¿quién es? ¿Es Zeus, es Djaus, es Yahvé, etc.?» ${ }^{28}$.

Mas, junto a esta defensa de las religiones como aproximaciones a la divinidad y a sus caracteres últimos, posibilitantes e impelentes (o radicales, donantes e impulsores), hay otros lugares en los que Zubiri sostiene la legitimidad y la necesidad de dar justificación racional, filosófica en particular, de Dios. Así como la filosofía puede extraviarse y dejar de considerar ciertos rasgos teístas abundantemente acreditados por las religiones, así también cabe la posibilidad de que las tradiciones religiosas lleguen a defender una idea insostenible de Dios. En este punto hay que ser sumamente precisos. No se trata sólo de que la idea de Dios elaborada por las religiones pueda ser inconsistente o contradictoria, pues cierta inconsistencia y contradicción caracterizan formalmente a toda idea teísta, una idea tan peculiar que no puede dejar de incluir propiedades intramundanamente irreconciliables. Prescindiendo de la interna inestabilidad de la idea de Dios, el problema es más bien que la mentalidad del sentido común puede extraviarse y pretender una disparatada o insensata noción de Dios. Más aún, puede llevar, al menos en principio, a una falsa idea de Dios. A reserva de abordar en otro lugar estas posibilidades: el disparate, la insensatez y la falsedad de la idea de Dios, aquí puede adelantarse que, según Zubiri, la posibilidad del error está circunscrita, de modo que no parece haber religión alguna que sea perfectamente falsa o cuyos sentidos sean completamente inadecuados. Con todo, esto implica que la razón religiosa puede extraviarse. Zubiri no se hace ilusiones al respecto. Por eso decía, en la sesión vigésimo primera del curso oral de 1948-1949 sobre «El problema de Dios», que «[...] sin un Dios probado por la razón, la fe de la más humilde religión terminaría por ser lo que no puede por menos de ser: una ingente vaguedad». No cabe más alternativa que reconocer que las religiones (Zubiri piensa sobre todo en algunos politeísmos y panteísmos) a veces atribuyen a lo divino unos caracteres que no son aceptables para la mentalidad teorética de la filosofía. Siendo posible detectar falsos caracteres teístas a lo largo y ancho de la historia de las religiones, las tres posibilidades de la razón religiosa (el politeísmo, el panteísmo y el monoteísmo) pueden y deben ser sometidas al juicio estricto de la razón filosó-

28 X. Zubiri, Naturaleza, Historia, Dios (Madrid, Alianza 2004), p. 413. Cf. también del mismo (n. 20), pp. 130-131. 
fica. En suma: todo esto implica que tanto los extravíos de las religiones como los de la filosofía han de ser decididos de acuerdo con el método de la razón. La concepción de Dios y su existencia no son prejuzgadas por la religación. Y ambas son campalmente irresolubles. El concepto de Dios ha de ser objeto de búsqueda en profundidad, y sobre su posible existencia o inexistencia únicamente la experiencia (allende la aprehensión) es capaz de decidir.

\subsubsection{La experiencia}

En todo caso, con independencia de estos posibles contenidos fundamentales de la divinidad, aquí solamente interesaba el análisis de la estructura racional y metódica del esbozo religioso. Pues bien: el 'producto' (sit venia verbo) de la búsqueda racional no son puras ideas, ni tampoco unos nombres o juicios, sino estrictas razones fundamentales. Si puede decirse que tanto el logos como la razón pretenden determinar el sentido del poder de lo real, hay que añadir que la razón, apoyada referencialmente en las sugerencias campales, busca el sentido de la posible realidad absolutamente absoluta objetualizada sobre el telón de fondo del mundo. La razón también es la búsqueda de una posibilidad, la posibilidad profunda de Dios como realidad transcendente y fontanal. El esbozo es la libre construcción de la posible razón fundamental de Dios. Mas, la posibilidad de la realidad transcendente y fontanal ha de ser sometida a prueba. Las distintas vías racionales esbozadas tienen que ser probadas y verificadas. ¿Cómo se transita desde el esbozo de la divinidad hasta la experiencia de Dios?

Zubiri tiende a pensar que se habla de experiencia religiosa con demasiada latitud. Bajo este título se incluyen cuestiones tan distintas como las ideas de Dios, los sentimientos acerca de algo sublime o sobrenatural y las vivencias místicas. A Zubiri le parece necesario hablar con la mayor precisión analítica que sea posible. Ya en los años cuarenta, en la décimo tercera sesión del curso sobre «El problema de Dios», dice que no hay una experiencia de Dios, que el problema histórico de Dios no está movido «por una más o menos difusa experiencia mística». Por eso declaraba de manera tajante que

«Lo único que me importa subrayar es que la experiencia del hombre a lo largo de la historia es justamente la experiencia misma de la búsqueda de Dios y, por consiguiente, de aquello que en esa búsqueda encuentra; cosa completamente distinta [...] a tener una experiencia de Dios, cosa enormemente problemática». 
A la altura de la trilogía, la cuestión de la experiencia religiosa puede ser reconstruida de manera analítica y no explicativa. Aunque sea inevitable recordar la obra de James, centrada ante todo en las numerosas y diversas vivencias psicológicamente descriptibles de la religiosidad (unas del individuo sano y otras del enfermo, unas constitutivas de la santidad, otras de la conversión, otras del misticismo, etc.), la exposición que hace Zubiri de la experiencia religiosa no es más que el análisis de ese momento metódico que consiste en probar físicamente la posible realidad profunda de Dios ${ }^{29}$. La razón hace de Dios realidad objetual, y por ende coloca a la realidad absolutamente absoluta sobre el telón de fondo del mundo. Esto no significa que Dios se vuelva un objeto sino sólo que se esboza metódicamente lo que Dios podría ser. Como realidad absolutamente absoluta, Dios no es ni puede ser un objeto intramundano. Campalmente aparece como una realidad plenaria que ha de recibir mayor determinación de notas y estructura, por libre construcción, en la realidad profunda. Por eso se tientan posibilidades de contenidos fundamentales para la divinidad. Desde la perspectiva de la razón, esta inserción del esbozo mundanal en la cosa campal ha de ser probada. La experiencia es aprobación o reprobación del esbozo. No es una pura prueba, un razonamiento más o menos silogístico (cosa que, en cualquier caso, no está excluida), sino el ejercicio físico de discernimiento en la realidad campal de Dios de la pertinencia del esbozo buscado y construido. Se discierne la realidad de Dios como momento del mundo o, mejor, como momento fundante del mundo. Al hablar del poder de lo real, se anticipó que la experiencia es uno de los momentos de la razón: la probación física de la realidad profunda del poder de lo real. Ahora, dentro del modo intelectivo racional, es posible abordar con detalle a la experiencia. La experiencia religiosa, como cualquiera otra, muestra la relación de funcionalidad que hay entre el campo y el mundo. La funcionalidad no debe ser adscrita solamente al campo sino también al mundo. Por eso mismo, la experiencia supone el esbozo, el lanzamiento desde el campo hacia el mundo, pero añade la inserción en el campo de las posibilidades fundamentales esbozadas. El esbozo es el resultado funcional de la marcha allende el campo: es lo que Dios podría ser. Y la experiencia es el resultado también funcional de la probación campal del esbozo mundanal. Tal probación conduce bien a la verdad, bien a la falsedad. En cualquier

29 Compárese este pasaje de Zubiri (n. 20), p. 326, con la obra de James sobre las variedades de la experiencia religiosa. 
caso, la probación del fundamento esbozado tiene una interna variedad, una modalización propia y una estructura peculiar.

Si hay una experiencia de Dios ceñible con rigor, dice Zubiri en el curso sobre «El problema de Dios», habrá de ser la probación de un camino variado e interminable, de una búsqueda por tanteos:

«Nadie ha visto a Dios, y lleva, sin embargo, en sí constitutivamente inscrito el problema de la búsqueda de Dios. De ahí que la historia del problema de Dios, y más generalmente la historia de las religiones, no es la historia mera y simple de unas preparaciones y de unas desviaciones; es el desarrollo gigantesco y titánico de un esfuerzo honrado con que el hombre ha pretendido encontrar luz y abrirse camino a tanteos, como dice san Pablo».

Cuando Zubiri habla de tanteos, habla propiamente. La cuestión de la experiencia es la de la probación llevada a cabo por una inteligencia sentiente. Es claro que todo esbozo racional de Dios conduce a una realidad estrictamente extramundana. Zubiri, sin embargo, se refiere a un tanteo en el camino hacia Dios, con lo que admite una suerte de percepción de Dios. Y aunque habla de la percepción dentro de la consideración del modo intelectivo primario de acceso a lo real, no hay que ceder a la tentación de creer que de Dios hay aprehensión primordial. ¿Qué se quiere decir entonces con 'percepción de Dios'? Dios es la posible realidad absolutamente absoluta. En tanto que realidad absolutamente absoluta, es para las cosas del universo y los hombres un fundamento. Quoad nos, Dios es realitas fontanalis. Ser fuente y fundamento significa estar fundantemente en el fondo de cada cosa. Vale decir: Dios es realidad absolutamente absoluta -es la ratio essendi de Dios-, pero el hombre sólo lo puede conocer experienciándolo como fundamento fontanal del poder de lo real y, por tanto, del yo y del ser - es la ratio cognoscendi de Dios- ${ }^{30}$. Desde el punto de vista de la experiencia humana, entonces, Dios es el que está fundantemente en el fondo de su realidad y de todas las realidades. La razón lleva a una realidad que es fuente del yo y del ser. Como realitas fundamentalis et fontanalis, Dios es transcendente, aun cuando sea inmanente al universo. Incluso fuera del ámbito de los monoteísmos es preciso admitir la transcendencia divina, pues la realidad de Dios, aun coincidiendo con la realidad universal, la sobrepasa y la supera precisamente porque la funda. Sólo es posible conocer a Dios, la realidad absolutamente absoluta (a diferencia de todas las demás, que

30 Cf. X. Zubiri (n. 20), pp. 172-174. 
son absoluta o relativamente relativas), en tanto que Dios es fontanal y es transcendente 'en' las cosas del mundo: «Dios es realidad absolutamente absoluta que es transcendente en lo real» ${ }^{31}$. De esta suerte, y sólo de ésta, Dios efectivamente no es percibido in modo recto, pero sí lo es in modo obliquo a través de la experiencia. Es toda la diferencia que hay entre la aprehensión primordial de realidad y la experiencia racional de ella. A Dios no se lo siente como una cosa cualquiera entre otras más, sino que se lo experiencia como la condición de posibilidad de todo objeto y de todo campo objetivo. La experiencia de Dios es la probación intelectiva y sentiente de que la realidad absolutamente absoluta es, en todas y cada una de las cosas del mundo, una realidad transcendente y fundamental. De Dios, por ello, hay una rigurosa «experiencia fundamental» $»^{32}$. Pero esta experiencia fundamental reposa en la aprehensión campal de la posibilidad de lo plenario y absoluto. Es cierto que la realidad divina es fundamental porque es absolutamente absoluta, pero en el orden del conocimiento no llegamos a la realidad reduplicativamente absoluta más que a través de su fundamentalidad:

«Dios es quoad nos et quoad omnes res una realitas fundamentalis. No es un ente supremo sino una realidad fundamental, absolutamente absoluta [...] Dios no consiste en ser una realidad fundamental. Dios sería realidad absolutamente absoluta, aunque no fundamentara. Y, recíprocamente, si tuviera que estar fundamentando para ser Dios, no sería realidad absolutamente absoluta» ${ }^{33}$.

La percepción de Dios no es directa. Las cosas son las que vehiculan una posible percepción experiencial de Dios. Si la inteligencia es sentiente aun tratándose de Dios, la experiencia es el momento de prueba de la posibilidad de esta realidad absolutamente absoluta y, por ello, fontanal y transcendente. La transcendencia divina es tal que permite al hombre una peculiar manera de sentirla y probarla. Es la experiencia de la realidad fundante de Dios, una probación vehiculada siempre y sólo por las cosas del mundo.

La indirecta percepción de Dios es la intelección sentiente que prueba la realidad profunda de Dios. Lo que la experiencia tiene de perceptiva se debe, pues, a que la razón es sentiente. Por esto, el método de la razón

31 X. Zubiri (n. 20), p. 311.

32 X. Zubiri (n. 20), p. 310.

33 X. Zubiri (n. 20), p. 311. 
religiosa prueba los esbozos teístas construidos a partir de las sugerencias campales. Y en dicha probación, la razón religiosa no está constreñida a ningún sentir concreto. En principio, todos los sentidos están involucrados en la experiencia de Dios. La posible realidad de Dios desborda todo contenido determinado. Como no se identifica en plenitud con ningún contenido en particular, ninguno de los sentidos está excluido de la experiencia de lo divino. Sentido alguno agota la realidad de Dios; en cada uno se puede aprehender imperfectamente esta inagotable realidad presente por transcendencia en las cosas. De ahí que la percepción indirecta que es la experiencia de Dios se refleje en todos los sentidos. Éstos son órganos de la percepción indirecta de Dios en tanto que experiencia de una posible realidad absolutamente absoluta, fontanal y transcendente en las cosas. La búsqueda por tanteos es también búsqueda por golpes visuales, noticias, gustos, etc. Empero, si bien todos los sentidos entran en operación cuando se trata de probar experiencialmente la realidad de Dios, hay algunos que adquieren una especial importancia. Zubiri destaca sobre todo a la audición, al tacto y a la direccionalidad. Las tradiciones religiosas y las vivencias místicas testimonian la primacía teologal de estos sentires. Digamos de paso que Zubiri menciona pocas veces el fenómeno místico, aunque cuando lo hace la referencia es normalmente significativa. Zubiri parece desconfiar del recurso irreflexivo al misticismo, quizá pensando -como Kant- que es frecuente confundir lo místico con fenómenos intensamente ambiguos, con un mero entusiasmo racionalmente ingenuo, o derechamente con patologías psicológicas, intelectivas y morales como en el caso del fanatismo ${ }^{34}$. Pero no siempre la alusión es desconfiada. En Zubiri se hallan también algunas referencias po-

34 Las cuatro observaciones generales que añade Kant en la segunda edición de La religión dentro de los límites de la mera razón tienden a alertar contra desviaciones ilusorias de la sana religión moral: la exaltación (Schwärmerer) en el caso de los efectos de la gracia (Gnadenwirkungen), la superstición (Aberglaube) en el caso de los milagros (Wundern), el iluminismo (Iluminatism) en el de los misterios (Geheimnissen), y la taumaturgia (Thaumaturgie) respecto de los medios de la gracia (Gnadenmitteln). Zubiri, claro, no puede sostener una concepción puramente racional y moral de la religión, que a sus ojos aparece como muy estrecha, aunque sí pudiera estar de acuerdo con Kant en los peligros aparejados al descontrol ético y racional de las religiones. En particular, Zubiri podría suscribir el llamado de atención acerca de las tentaciones iluministas que acechan a la religiosidad. Y es que en el terreno huidizo de los misterios puede originarse esa idea exaltada (überschwengliche Idee) que Kant llama iluminismo o también ilusión de los adeptos (Adeptenwahn), y que consiste en «la ilusoria iluminación del entendimiento (gewähnte Verstandeserleuchtung) en relación con lo sobrenatural (misterios)» (vid. B 64). 
sitivas a los místicos en las que se subraya bien la profundidad especulativa de su imagen de la divinidad, bien el carácter paradójico de la experiencia religiosa, bien su faceta intensamente sentiente. $\mathrm{Y}$ es esto último lo que ahora podemos advertir: que la mística parece concordar masivamente en la relevancia teísta de los sentires. Para Zubiri, los místicos han mostrado que el tacto y la audición son modos de acceso a Dios:

«Algunas veces, los místicos han apelado a un tipo de intelección que no es visual, pero han caído en la intelección táctil. Por ejemplo, cuando Juan de Santo Tomás describe la presencia de Dios en el alma del místico, acude a la metáfora táctil: alguien llama a una puerta, pero no se hace presente» ${ }^{35}$.

«Ya san Juan de la Cruz decía que Dios está presente al alma en forma de llamada, sin que se manifieste lo que es en sí mismo: es la nuda presencia de la realidad. Pero en la medida en que es presencia de realidad se trata de un sentir intelectivo» ${ }^{36}$.

En todo caso, más allá de los testimonios místicos, es el análisis el que muestra por sí mismo la relevancia teologal de los tres sentidos mencionados. Si el poder de lo real toca al hombre, la experiencia religiosa es la probación física de una suerte de toque divino, para decirlo con el vocabulario de la mística sanjuanista. Zubiri dice que «la historia de la religión es por esto un tanteo, un gigantesco tanteo del espíritu humano» ${ }^{37}$. Un toque, claro, de una realidad que llama sin hacerse presente en sí misma, pura manifestación 'a una' quemante, sutilísima e irrepresentable. Por otro lado, del poder de lo real hay una noticia indefectible, que es la voz de la conciencia. La experiencia religiosa es la probación de esa voz de la conciencia como la voz poderosa e irrefutable de Dios mismo. Por eso Zubiri habla incluso de un latido, de una palpitación sonora de Dios en la vida humana ${ }^{38}$. Esta presencia auditiva de la divinidad es casi correlativa a la imposibilidad de ver a Dios. Y es que mientras el oído está sometido

35 X. Zubiri (n. 11), p. 66. Antes, Zubiri ha hecho otra alusión a la mística, aunque con ella parece enfatizar solamente que la deidad está envuelta y reflejada incluso en las cosas más nimias: «¿Quién no recuerda la célebre frase de santa Teresa que decía que el Señor está entre los pucheros? Realmente, el místico encuentra a Dios no como una cosa más entre las demás cosas, sino como algo que refleja en todas ellas eso que llamamos el carácter de deidad» (n. 11), p. 59.

36 X. Zubiri, Los problemas fundamentales de la metafísica occidental (Madrid, Alianza 1994), p. 340.

37 X. Zubiri (n. 11), p. 365.

38 Cf. X. Zubiri (n. 11), pp. 66-68, 147, 304-305, 347 y 365. 
y lanzado hacia lo escuchado, la vista domina e incluso llega a definir lo visto. De ahí que Dios sea principalmente noticia que saca al hombre fuera de sí mismo, sometiéndolo a lo que resuena, y no un objeto dominado por la visión eidética. Esto no impide, al menos en línea de principio, la existencia de un eîdos de la divinidad, pero sí relativiza y restringe severamente su ámbito de validez. Hay un eîdos en las representaciones teístas campales y racionales, pero Dios se manifiesta sobre todo auditivamente como el que habla o el que calla. Tercero, el poder de lo real está sentido siempre de manera direccional, como ese dominio que nos lanza a una búsqueda fundamental interminable. La experiencia religiosa es la prueba de si esa búsqueda encuentra o no encuentra a Dios como fundamento absolutamente absoluto del poder de lo real. Es decir, la probación de Dios es una marcha dirigida por el esbozo de la realidad plenaria, transcendente y fontanal, cuyo término infinito, de ser alcanzado, daría razón del camino emprendido. Dios mismo no es sólo el término de la marcha sino el desencadenante de esta búsqueda intelectiva sin fin, siempre tensa y oscilante entre alternativas radicalmente diversas y paradójicas. Zubiri resume así la relevancia teologal de estos tres sentires:

«Este Dios no es un dato interno de la consciencia ni tan siquiera un objeto. Sin embargo, está presente en forma [...] auditiva: de él tenemos noticia. También tenemos un cierto tanteo, un cierto tacto. $Y$ en su virtud estamos lanzados hacia la propia divinidad. En este 'hacia' está inscrita, no de manera azarosa sino intrínseca y esencial, la posibilidad de múltiples vías» ${ }^{39}$.

La experiencia de Dios se asienta en toda la variedad de la intelección sentiente, concentrándose especialmente en estos tres sentires. La probación de la realidad divina es, pues, la percepción indirecta de su transcendencia en las cosas y en la vida humana. Tal percepción es característica de la experiencia religiosa, particularmente de su dimensión mística: «Jamás, ni en el acceso supremo de los grandes místicos, se accede a Dios sin las cosas o fuera de ellas: se accede siempre a Dios en las cosas $»^{40}$. Resumiendo: todos los sentires, en especial el oído, el tacto y el sentir direccional, permiten probar racionalmente la posibilidad de la realidad absolutamente absoluta a través de su carácter transcendente y fundamental. Justo por la manifestación de la realidad divina, hay una cierta audición y un cierto tacto de Dios. Dios no se manifiesta como algo situado ante la vista, un

39 X. Zubiri (n. 11), p. 147 (vid. pp. 64-68).

40 X. Zubiri (n. 20), p. 186. 
objeto que estuviera 'delante', sino como esa realidad misteriosamente excesiva que se hurta a la mirada y que sólo se puede oír y tantear. Al estar Dios 'en' las cosas sin identificarse con ellas sino transcendiéndolas, estas cosas remiten a Dios dándonos noticia de su realidad absolutamente absoluta: «Por esto es por lo que la manera propia de manifestarse lo transcendente en cuanto transcendente es remisión notificante, manifestación de tipo 'auditivo'» ${ }^{41}$. Esta manifestación peculiar y única es no sólo auditiva sino también táctil. La nuda presencia de Dios es la manifestación de la realidad divina como tanteo: «No dejándose ver, pero sí haciendo sentir inmediatamente su nuda presencia en una especie de llamadas con los nudillos en la puerta del hombre» ${ }^{42}$. El oído y el tacto, aplicados a Dios, sumergen al hombre en una marcha que no tiene término y que no puede ser comparada con ninguna otra búsqueda racional. La direccionalidad afecta intrínseca y eminentemente a los sentires cuando intentan probar físicamente a Dios. En todas sus variantes, es la prueba de un esbozo de lo que Dios podría ser. El propio Zubiri lo sintetiza así:

«La religación, decía, es una experiencia manifestativa del poder de lo real. Y esta experiencia nos lanza experiencialmente hacia su fundamento en las cosas mismas, hacia Dios en ellas. Y lo que este Dios tiene de manifestativo es serlo en forma audio-táctil, esto es, a un tiempo como noticia y nuda presencia por tanteo» ${ }^{43}$.

1 X. Zubiri (n. 20), p. 189.

42 X. Zubiri (n. 20), p. 190.

43 X. Zubiri (n. 20), p. 190. No está de más notar la semejanza de esta idea de la percepción indirecta de Dios con la siguiente idea de experiencia transcendente: «La experiencia transcendente es una percepción sensible de lo infinito en una circunstancia determinadas: L. Roy, Experiencias de trascendencia. Fenomenología y crítica (trad. C. Castells, Barcelona, Herder 2006), p. 27. Pero se trata sólo de una semejanza, porque esta experiencia no se identifica con la religiosa. La experiencia transcendente es una noción en parte descriptiva y fenomenológica (vid. pp. 23-58), en parte constructiva y elaborada en diálogo histórico con pensadores modernos (vid. pp. 59-218), pero finalmente -solidaria como es de las ideas de Maréchal, Rahner y especialmente Lonergan- aboca a una suerte de analítica del sentido de los conceptos (vid. pp. 219-310 y 317). Así, desde la perspectiva de un teísta, la experiencia transcendente sería más estrecha que la religiosa, porque el reconocimiento afectivo de una realidad suprema -característico de la experiencia transcendente- no agota el espectro de los actos religiosos, mientras que desde la perspectiva de un ateo, un agnóstico o un indiferente ocurre justamente al revés: más estrecha sería la experiencia religiosa, porque allende los contextos interpretativos y prácticos de las religiones hay todavía un amplísimo terreno de experiencias transcendentes, sean estéticas, ontológicas, éticas o interpersonales (vid. pp. 25-26 y 35-37). Con todo, hay que destacar que la experiencia 
Estos tres sentires, por fin, se recubren entre sí, y su recíproco recubrimiento consiste en algo así como la fugitiva pero abrumadora manifestación auditiva y táctil de Dios, cuya noticia y nuda presencia ponen al hombre en marcha existencial e intelectiva hacia el fondo inagotable y misterioso de la realidad absoluta e infinita presente transcendentemente en toda realidad. La analogía y la paradoja son, en la experiencia, contacto con una realidad abrumadora que se escapa, noticia de esa realidad irrefragable cuya voz se intelige por una aproximación sumamente desajustada, y dinamicidad de la realidad a la que el hombre está lanzado en una dirección interminable y abismática.

Tener una experiencia religiosa equivale, así, a tener una prueba 'a una' intelectiva y sentiente de Dios. Pero esto no es todo. La experiencia no es privativa de la intelección sentiente, sino que se despliega en las estructuras que ella determina: el sentimiento afectante y la volición tendente. La probación es un momento del método racional, pero tiene unas ostensibles estructuras sentimentales y volitivas. La intelección probadora de Dios desencadena un proceso en el que hay sentimientos y voliciones. Esto es especialmente claro cuando se aborda la modalidad y la estructura de la experiencia de Dios. Todos los momentos del método religioso están modalizados. Hay diversos modos de objetualidad y por ende distintas categorías de realidad: unas son las cosas, otras los vivientes y otras las personas. Dios es también una posible realidad campal que, proyectada sobre la realidad del mundo, se transforma en una realidad objetual. Como un particularísimo modo de objetualidad y de categoría, Dios es una realidad cuyo contenido fundamental ha de ser buscado en profundidad. Esta búsqueda está determinada por un preciso sistema de referencia: el poder de lo real representado campalmente como realidad absolutamente absoluta. El sistema de referencia es tan elusivo y fundamental como el poder de lo real en el campo. Esta peculiaridad modal

religiosa es una experiencia completamente sui generis. Hablamos de una percepción indirecta de Dios justamente por la enorme, absoluta diferencia que hay entre el que experimenta y aquello que experimenta, una diferencia que hace que Dios sea experienciado paradojalmente como la realidad máximamente real y encontradiza y 'a una' como la realidad máximamente desbordante y huidiza. Es algo que la mística y la historia de las religiones documentan con abundancia; para Tauler, por ejemplo, se puede calificar a la espiritualidad cristiana como experiencia (probación, sentir, degustación, etc.) y a la vez como no experiencia (desolatio, abandono, pérdida, noche, sequedad, oscuridad, etc.) de Dios: vid. la exposición que hace H. U. v. Balthasar, Theodramatik Vol. 4: Das Endspiel (Einsiedeln, Johannes 1983), pp. 409-412. 
del sistema de referencia lleva a un esbozo también modalizado. Entre el esbozo y el concreto contenido representativo del campo puede haber una relación de conformidad, de contrariedad, de mera diferencia o de superación. Si no se toma ese concreto contenido representativo sino sólo su forma más básica, habría que decir que, dentro del teísmo, la relación entre esbozo y sistema referencial es de conformidad y superación. Pero si se desciende a las particularidades de cada representación, se ve que caben esbozos contrarios o meramente diversos del sistema de referencia. En efecto, el esbozo toma como punto de partida a Dios como realidad absolutamente absoluta, transcendente y fontanal; es justo lo que permite hablar de religión a diferencia de otros sentidos otorgados al poder de lo real, por muy próximos a la religión que éstos sean. La religión es una plasmación teísta de la religación. Donde no se reconoce una realidad absolutamente absoluta, totalmente otra y fundamento del poder de lo real, simplemente no estamos en presencia de un fenómeno religioso. Otra cosa es la interpretación precisa que se dé de esta realidad plenaria, dentro de la cual caben muy diversas orientaciones intelectivas, pero sin dicha realidad plenaria el discurso religioso no sería mínimamente inteligible. Es, por así decir, el núcleo duro de todo sentido (campal y mundanal) acerca de Dios. Empero, esto no es más que el momento más básico de todo sentido y esbozo teísta. Los mismos sentidos incluyen otra serie de ingredientes intencionales, más o menos coherentes con la realidad de Dios así determinada. Todo esto sería ya el contenido débil y cambiante de los sentidos de Dios. Las representaciones y los esbozos tienden a precisar y enriquecer en alguna dirección el contenido de la divinidad como realidad absolutamente absoluta, transcendente y fontanal. Por esto mismo las concretas representaciones campales divergen más o menos entre sí, tal como divergen entre sí los esbozos de la razón. También ha de notarse cuánto contradicen o al menos se separan los esbozos de los sentidos teístas campalmente construidos. Zubiri, me parece, interpretaría toda esto como la diversidad de los contenidos débiles y cambiantes de la realidad de Dios. Así, no es extraño que dentro de una misma tradición religiosa la teología discuta los contenidos representativos otorgados a la realidad divina por la mentalidad del sentido común. Más aún entre distintas tradiciones, porque entonces cada teología suele enfrentar críticamente tanto a las otras mentalidades religiosas del sentido común como a las otras teologías. Y en la ciencia y la filosofía, por su propia pretensión de neutralidad e imparcialidad religiosa, también se producen discusiones 
y contradicciones cuando se estudia el lenguaje de las religiones. Ciencia y filosofía no pueden menos que poner en tela de juicio muchas construcciones campales de la divinidad, no necesariamente desde el punto de vista de una determinada religión, sino tan sólo desde los fueros de una razón históricamente ilustrada y éticamente justificada. En fin. Basta con señalar las modalizaciones de cada momento metódico; no es preciso, en un estudio analítico y formal del método de la razón religiosa, detenerse en los innumerables ejemplos posibles de modalización.

Las modalizaciones del método abocan finalmente a la experiencia. Cualquier experiencia del poder de lo real es de una riqueza y complejidad máximas. Zubiri podría decir que la experiencia religiosa es «muy rica y compleja ${ }^{44}$. Por eso es una experiencia simplemente viable, en caso alguno una experiencia obvia. Pero tanto la experiencia viable como la obvia parecen ser experiencias de cosas intramundanas. Si esto es así, ¿es la experiencia religiosa, en rigor, una experiencia clasificable dentro de alguno de los cuatro modos de experiencia de lo viable? Creo que, de acuerdo a Zubiri, se pueden encontrar dos rasgos básicos en la experiencia religiosa. Por una parte, es efectivamente una experiencia, una probación física de la realidad profunda, y como tal tiene una faceta intramundana, aunque su verificación sea no sólo abierta sino también especialísima. Si toda experiencia es esencialmente intramundana, pueden investigarse por ello los rasgos intramundanos y los modos de probación que son característicos de esa experiencia única e inclasificable que es la religiosa. Mas, esto último nos muestra la otra cara de la experiencia de Dios. Aunque es una experiencia, lo experienciado en ella es esencialmente heterogéneo. Tan sui generis es, que no calza del todo dentro de ningún modo experiencial intramundano. Es la experiencia de la realidad de Dios, de algo toto caelo distinto de la realidad del yo y del ser. De ahí que no haya respectividad recíproca entre Dios y el mundo: el mundo es respectivo a Dios, pero Dios es irrespectivo al mundo, es esencialmente ultra o extramundano. Como tampoco hay recíproca respectividad entre Dios y el hombre: el hombre es respectivo a Dios, pero no a la inversa. Así, pues, creo que Zubiri podría abordar la experiencia de Dios de la siguiente manera. La experiencia religiosa, como probación de alguna clase de esbozo teísta, es siempre una experiencia por conformación, pues en ella se obtiene un conocimiento de sí mismo a la luz de lo que ese sí mismo podría ser en el fondo ${ }^{45}$. El

44 X. Zubiri (n. 4), p. 247.

45 Vid. A. Pintor-Ramos, Religación (n. 1), pp. 335-336. 
esbozo del contenido fundamental de la realidad divina es una libre construcción desencadenada por el dominio del poder de lo real que fuerza a la realización de la persona. Y la experiencia de ese esbozo es la experiencia del fundamento en el yo, en la concretísima vocación del yo ${ }^{46}$. La religión es una experiencia por conformación porque es probación del fondo de la propia realidad en función de Dios. Sin embargo, el fundamento no sólo funda a la persona sino a toda la realidad mundanal: allende el ser, es en todo caso fuente del ser. Por eso en la experiencia religiosa es probada la propia realidad, y la realidad de todas las cosas, en función de la realidad fundamental de Dios. La conformación es experiencia del yo en el mundo, y cuando esta conformación es religiosa, el sentido del mundo in toto -el ser- es probado en su respectividad para con el hombre. Es cierto que en la conformación se discierne si la realidad profunda aprueba o reprueba tal o cual esbozo de la persona humana. Pero lo que está en juego en los esbozos religiosos es el sentido de la realidad de alguien dentro del conjunto mayor del sentido de la realidad qua realidad. La razón religiosa lleva, pues, a la probación de un sentido teísta como fundamento del yo y del ser mismo. La religión es, entonces, una experiencia por conformación. De todas formas, hay experiencias por conformación que no son religiosas. Es el caso de las experiencias morales. La diferencia entre moral y religión es la diferencia entre dos líneas de conformación del yo: la primera es la probación del fondo de la propia realidad en función de otra realidad relativa (sea la propia en tanto que otra, la de los demás seres humanos, o incluso la de otros animales o vivientes), y la segunda es la probación del fondo de la propia realidad en función de la realidad plenaria, de Dios. Esto no prejuzga la posibilidad de que ambas líneas se entrecrucen y mezclen en mayor o menor medida ${ }^{47}$.

46 Por esto Zubiri no parecería aceptar una verificación histórica, como si la religión fuese primo et per se una cosmovisión de la totalidad de la realidad y la historia (como piensa Pannenberg). La verificación, en verdad, sólo puede ser concreta, y consistir en la probación real de la fundamentación religiosa del hecho de la religación (como lo vislumbró Bonhoeffer): «Si bien no podemos tener experiencia de Dios, sí podemos ser experiencia de Dios, viviendo nuestra vida ligados a Aquél que hemos postulado como el fundamento último del poder de lo real»: A. GonZÁLEZ, «Aproximación a la filosofía zubiriana de la religión», en J. A. Nicolás y O. Barroso (eds.), Balance y perspectivas de la filosofía de X. Zubiri (Granada, Comares 2004), p. 277 (vid. en gral. pp. 275-277).

47 En un sentido semejante se ha dicho que «[...] la experiencia religiosa propiamente dicha es, a mi entender, la experiencia del don o de la gracia. La experiencia de la religación se hace experiencia religiosa cuando pasa de ser experiencia del poder a 
Sin embargo, la conformación es sólo un aspecto de la experiencia religiosa. Ésta es una experiencia de aquello máximamente heterogéneo, una experiencia paradójica, porque en ella se vuelve patente que lo más íntimo -lo que conforma la propia realidad- es a la vez lo más otro. A su manera, ocurre algo parejo en la religación humana, y también -más en particular-con los místicos. En el siguiente pasaje, Zubiri vuelve a citar a «todos los místicos» por mediación de Otto:

«Lo numinoso en este sentido es totalmente otro, lo totalmente otro. De ahí que envuelva precisamente esa estructura paradójica y antinómica en la que se complacen todos los místicos» ${ }^{48}$.

El poder de lo real es 'a una' el fondo intimísimo del hombre y lo más ajeno a su realidad. Y la posibilidad de Dios campalmente representada y mundanalmente fundamentada es también (y por lo mismo) la de la realidad más propia y más extraña. Por eso los esbozos religiosos también pueden ser sometidos a otro modo de probación, en el cual la alteridad se combina con la intimidad del yo. Es la experiencia por compenetración de las religiones que esbozan un Dios que es persona. En ella se incluyen, por supuesto, las tres dimensiones del ser humano: la individual, la social y la histórica. Y es tan amplia la compenetración que también puede abarcar los lazos de una persona con los seres vivos. En general, este modo experiencial pone en esencial vinculación a la realidad de una persona con la de otra. La probación de la realidad de la otra persona, e incluso de la otra vida, es también constitutiva de la propia realidad personal. La experiencia del yo incluye una experiencia de la realidad ajena. La religión es una experiencia por compenetración porque puede ser probación del fondo de otra realidad personal o vital ${ }^{49}$. La compenetración enfatiza que la experiencia religiosa es la experiencia de otra realidad, y no solamente una conformación de la realidad propia. Ya lo insinuábamos cuando ha-

ser experiencia de la gracia. Pues bien, si ésta es, como yo creo, la esencia de la experiencia religiosa, entonces hay que decir que es muy distinta, completamente distinta a la experiencia moral. La experiencia moral no es la experiencia de la gracia sino la experiencia del mérito. Si yo hago algo, merezco que se me retribuya. La experiencia moral se basa siempre en el concepto de reciprocidad, de equidad, de compensación, etc.», D. GRACIA, «Religión y ética», en Como arqueros al blanco. Estudios de bioética (Madrid, Tricastela 2004), p. 143 (vid. en gral. pp. 143-149). X. Zubiri (n. 11), p. 21. Es indudable que donde Otto acude a lo numinoso Zubiri se referiría a lo divino.

49 En este sentido vid. D. Gracia, Voluntad (n. 1), pp. 229-232, y Religación (n. 1), pp. 498-499, e incluso Pintor-Ramos, Religión (n. 1), p. 397. 
blábamos de la religión como conformación: es la determinación del yo apoyada en la postulación fundamental de la realidad divina. Se conforma el yo en función de Dios. En la conformación ya está la absolutamente absoluta alteridad divina. Pero en la compenetración esto llega a su ápice. Dicha experiencia no sólo incluye a la alteridad sino que la alteridad es su constitutivo formal. Es tan así que en este modo experiencial habría que invertir las cosas y decir que, si bien la compenetración es experiencia de otra persona, no excluye sino que incluye a la propia persona. Podría llegar a admitirse que la experiencia religiosa, justo por la alteridad total de Dios, tiene un intrínseco coeficiente de negación y suspensión, y que es -al menos en parte- una experiencia a la vez negativa y suspensiva ${ }^{50}$. La propia realidad personal prueba lo que otra realidad personal o vital (la persona otra o la otra vida par excellence) podría ser en el fondo. Mas, este énfasis ( $\tan$ legítimo) de lo extraña que es la persona o vida de Dios no debe pasar por alto que Dios, el otro absolutamente absoluto, no es siempre ni necesariamente una persona o una realidad viva. Zubiri alguna vez parece advertirlo: «Dios es realidad absolutamente absoluta, y en tanto que absolutamente absoluta es como está fundamentando las cosas, aunque en esta fundamentación no entren formalmente el carácter de inteligencia y el carácter de voluntad $»^{51}$. Si ya se extreman las cosas cuando se dice que toda religión es teísta, incluso las aparentemente ateas, se las forzaría injustificablemente si se dijera además que toda religión es un vínculo entre la persona relativamente absoluta y una persona o una vida absolutamente absoluta. No toda religión incluye un esbozo personal o vital de Dios. Sólo cuando éste es el caso, la religión incluye una experiencia no sólo por conformación sino además por compenetración. La experiencia religiosa es, entonces, una experiencia entre dos personas o dos vidas, la humana y la divina. Es claro que en sus análisis de la experiencia religiosa, Zubiri tiende a privilegiar esta experiencia por compenetración, pese a que ella no es propia de toda experiencia religiosa sino sólo un caso particular de ella. Así, por ejemplo, se refiere a la experiencia histórica que hizo Israel de Yahvé como un ejemplo de experiencia por compenetración ${ }^{52}$. Zubiri recurre incluso a una noción de la teología trinitaria cristiana para decir que la compenetración «es una especie de perikhóresis, no de realidad pero

\footnotetext{
50 Cf. X. Zubiri (n. 4), p. 276.

51 X. Zubiri (n. 20), p. 311.

52 Cf. X. Zubiri (n. 4), pp. 250-251.
} 
sí de modos de actuar, y de conducirses ${ }^{53}$. Aun cuando Zubiri hable de la personalidad divina empleando analógicamente la categoría de persona ${ }^{54}$, no puede aceptarse que Dios sea siempre y en todo caso una persona. Incluso si se acepta que la compenetración proporciona un modelo excelente de comprensión de la experiencia religiosa, ha de agregarse que no toda religión es experiencia por compenetración. $\mathrm{Y}$, también, que no toda compenetración es religiosa: cualquiera vinculación entre personas o entre éstas y otros vivientes, como el cuidado, la amistad o la política, es una mejor o peor experiencia por compenetración.

Esencialmente modalizada como conformación y a veces también como compenetración, la experiencia religiosa es intelectiva (y sentiente), sentimental (y afectante) y volitiva (y tendente). Por ello tiene una estructura sumamente peculiar. La experiencia no es mero esbozo de Dios, sino prueba sentiente, intelectiva y existencial de ese esbozo. Esta probación es heterogénea y única porque lo experienciado, Dios, es heterogéneo y único. Se ha de probar si las posibilidades buscadas y libremente construidas permiten conformar con mayor fundamento la propia realidad en función de la realidad absolutamente absoluta, y -en algunos casos- si dichas posibilidades franquean una compenetración de la propia persona con el fondo personal o vital de la divinidad. La inserción del esbozo en el campo es, bien la inserción de la realidad de cada cual en un mundo real fundado en Dios, o bien la inserción de la realidad de Dios, el fundamento del ser y del yo, la realidad más próxima y la más lejana, en la propia vida. Esta descripción genérica de la experiencia de Dios conoce muy diversas posibilidades. Como hemos visto, se prueban esbozos enormemente distintos, unos más bien politeístas, otros panteístas y otros monoteístas. Dentro de cada uno de estos grupos hay diversas rutas posibles. De ahí que sólo en algunas religiones la experiencia recaiga sobre un esbozo personal o vital de Dios. En todo caso, la experiencia de Dios requiere al ser humano por completo, es «una opción radical del hombre» ${ }^{55}$. En la experiencia religiosa la prueba de Dios es 'a una' probación del propio

53 X. Zubiri (n. 4), p. 250.

54 «El carácter de persona aparece con un matiz puramente analógico. No se trata de concebir a Dios como una especie de gran señor o de gran persona que tiene en sus manos el cubilete del mundo que ha creado. El concepto de persona es meramente analógico. Dios es una realidad que se posee plenariamente a sí misma, y por consiguiente tiene carácter personal»: X. ZuBIRI (n. 11), p. 69.

55 X. Zubiri (n. 11), p. 162. 
yo a la luz de la realidad absolutamente absoluta. Lo es, claro, porque es prueba del fundamento del poder de lo real, que es último, posibilitante e impelente. El apoyo a tergo en que consiste el poder de lo real es probado como Dios en la vida del hombre. Como no hay probación más comprometedora y absorbente, la experiencia religiosa supone un acto optativo y radicalísimo de confianza. Con esto tocamos una peculiaridad estructural de la experiencia religiosa. La experiencia de Dios equivale a confiar en la divinidad postulada para determinar y orientar la propia realidad en el mundo. La experiencia religiosa es, así, una forma de confianza. Por eso Zubiri dice que toda experiencia de Dios, debido a su estructura, es una fe. Probar el esbozo equivale a confiar en la realidad divina postulada no sólo como fundamento del poder de lo real, sino como fundamento del sentido de mi realidad (el yo) y también de la realidad del mundo (el ser). La fe es entrega, aunque no siempre sea entrega a la persona o vida de Dios. Pese a ello, en la definición de la fe Zubiri privilegia una vez más a las religiones que postulan a un Dios personal. Por eso dice que la fe es la entrega de una realidad personal a otra realidad personal. Más bien debiera decirse que aunque no sea siempre una compenetración personal y vital, la religión sí es una muy particular entrega del yo a la divinidad. Por ser conformación, entonces, la fe es una forma de realización del propio yo. $Y$ sin ser necesariamente compenetración, la fe es una forma de entrega del yo a la realidad absolutamente absoluta. Por lo primero, la fe es la determinación del fondo de la persona humana en función de la realidad absolutamente absoluta, y por lo segundo, es la entrega de la primera a la segunda, sea ésta personal o vital o no. Por el momento conformador, se enfatiza que lo esbozado es el fondo de la propia realidad en función de Dios, y por el momento de entrega, que lo esbozado es la realidad divina en tanto que en ella puede deponerse la entera realidad humana. Tomadas estas determinaciones en conjunto, puede decirse que el esbozo politeísta, panteísta o monoteísta de la realidad más ajena y más íntima de todas conforma de una manera particular el esbozo que el hombre hace de sí mismo. La fe religiosa es la confianza en la realidad de Dios para conformar la dirección vocacional de la propia realidad y como término al cual ésta puede entregarse. Es, en breve, confianza para realizar la propia realidad a la luz de Dios, y por eso mismo confianza para entregarla a Dios.

$\mathrm{Si} \mathrm{la} \mathrm{fe} \mathrm{es} \mathrm{confianza,} \mathrm{la} \mathrm{estructura} \mathrm{de} \mathrm{la} \mathrm{experiencia} \mathrm{religiosa} \mathrm{es} \mathrm{la} \mathrm{de} \mathrm{una}$ creencia. Zubiri parece seguir los estudios de Ortega acerca de las ideas 
y las creencias ${ }^{56}$. Como Ortega, Zubiri caracteriza a la fe en cuanto tal como creencia en la que se está, y no como una mera idea que se tiene. La fe es confianza y entrega firme, y por eso es creencia en la que se está. La fe religiosa es la creencia en una realidad absolutamente absoluta a la que el hombre se puede entregar confiadamente para así determinar su propia realidad profunda. Confiar es tener fe, y tener fe es creer. La primordial voluntad de verdad real que puede acompañar a la religación es para la razón una voluntad de fundamentalidad, una voluntad que busca lo que el poder de lo real podría ser en el fondo. Cuando esta volición es teísta, se cree que el poder de lo real tiene por fundamento a la realidad absolutamente absoluta. Mas, Zubiri admite la posibilidad de una creencia que no compromete a la realidad humana, una fe 'floja'. La experiencia religiosa, entonces, puede ser vivida no como una búsqueda del fundamento divino qua fundamento último, posibilitante e impelente para el ser humano, sino como una búsqueda de él que en nada afecta esencialmente al hombre, una búsqueda del fundamento como mero objeto ocioso. Cierto es que la primera opción es la más racional, ya que es más coherente con el poder de lo real. De todas formas, según Zubiri, el fenómeno religioso de los dii otiosi enseña que, aun siendo racionalmente deficiente, es perfectamente posible que la voluntad de fundamentalidad sea objetivadora, y que en ella se suspenda o reduzca la relevancia existencial del fundamento divino. En la religión, por tanto, la opción y la creencia llevan a un Dios fundamentante cuando son plenamente racionales, pero cuando no lo son constituyen una fe deficiente y llevan a un Dios ocioso ${ }^{57}$. La religión más racional, así, sería la que tiene la experiencia de un Dios personal y vivo que fundamenta la existencia. Pero esto ya es metafísica; si se vuelve al hilo analítico que aquí se ha seguido, puede decirse, aunque Dios no sea persona viva, que la fe comprometedora en una divinidad no ociosa no es un mero abandonarse sino la entrega enérgica, un arrastre querido: «la persona acepta desde sí misma éste su ser llevada de un modo activo y positivo, a saber, 'va a Dios'» $\rangle^{58}$. La firmeza de esta entrega del ser humano a la divinidad adopta unas figuras particulares, estrechamente ligadas con la ultimidad, la posibilitancia y la impelencia del poder de lo real, y con Dios en cuanto sostén formal, raíz donante y forzoso impulsor de la

\footnotetext{
56 Cf. J. Ortega y Gasset, Obras completas Vol. 5: 1932-1940 (Madrid, Taurus 2006), pp. 659-685.

57 Cf. X. Zubiri (n. 20), pp. 260-261.

58 X. Zubiri (n. 20), p. 198.
} 
vida humana. A la ultimidad sostenedora de Dios corresponde el hombre con esa forma de entrega que es el acatamiento. A Dios como donante de posibilidades corresponde el hombre con la súplica. Y a la impelencia divina corresponde la entrega del hombre que se refugia en Dios ${ }^{59}$. Si en el campo del logos se tienen ideas de Dios, en el mundo de la razón (cuando es plenamente racional) se está con ciertas creencias sólidas y comprometedoras acerca de Dios. Así es como la actualización profunda de un sentido teísta conduce a la experiencia creyente.

Empero, no hay que perder de vista que el ateo y el agnóstico son creyentes, como creyente es el hombre religioso, y que no toda fe es religiosa. Para Zubiri, como para Ortega, la fe no es exclusiva de la experiencia religiosa, sino de toda experiencia humana en tanto que encara y no puede dejar de encarar el problema de Dios, aun bajo la forma de la desprocupación y la indiferencia, o del agnosticismo y el ateísmo. La experiencia universal de la fe expresa una misma voluntad de fundamentalidad. De ahí que también el ateo tenga fe: «El ateísmo es justo la fe del ateo» ${ }^{60}$. Hay «una fe tanto religiosa como meramente humana» ${ }^{61}$. Por lo mismo, «el ateísmo y el agnosticismo no son menos creencias que el teísmo» ${ }^{62}$. Zubiri, como se ha dicho, coincide con la tesis de Ortega acerca de la estructura creyente de toda existencia humana; por ello, aun si el agnosticismo incluyera no sólo la ignorancia en torno a Dios sino también el barrunto y la duda a su respecto, habría que decir que el que ignora a Dios, el que lo barrunta y el que duda de él están en su actualización indeterminada, indicial y ambigua creyentemente. En cualquier análisis de las construcciones racionales religiosas e irreligiosas se ve con nitidez que el hombre depone todo su ser en una determinada postulación fundamental. Y a la inversa, se ve que postular un contenido fundamental para cualquiera de los sentidos campales otorgados al poder de lo real no es más que ejecutar un acto de construcción racional en el que al hombre le va todo su ser. Hay fe religiosa y fe no religiosa, pues tanto la una como la otra son creencias en las que se está y, por ello, son entregas más o menos firmes y confiadas a lo creído. La creencia acompaña a toda vida humana, y por eso mismo siempre hay en ella una elemental voluntad de fundamentalidad. Mas, aunque el ateo y el agnóstico tienen fe, y creen y prueban determinados esbozos

59 Cf. X. Zubiri (n. 20), pp. 199-200; del mismo (n. 11), p. 243.

60 X. Zubiri (n. 20), p. 284.

${ }^{61}$ X. Zubiri, Inteligencia sentiente: Inteligencia y logos (Madrid, Alianza 1982), p. 223.

62 X. Zubiri (n. 20), p. 12. 
acerca de lo que el poder de lo real podría ser, sin embargo no tienen una fe religiosa. En todo caso, sus creencias son perfectamente razonables. La voluntad de verdad es una voluntad de fundamentalidad. Y esta voluntad de fundamentalidad se modula de distintas maneras. En el agnóstico es voluntad de buscar, tal como en el teísta. Pero mientras en éste la marcha lo lleva de manera razonable a tomar su propia opción religiosa, dentro de la cual todavía es posible un conocimiento más o menos demostrativo de la realidad plenaria de Dios, en el agnosticismo la marcha conduce a la ignorancia e incognoscibilidad de Dios, incluso (en la noción amplísima que acabamos de admitir) a meros barruntos o puras dudas con respecto a su realidad plenaria, y en cualquier caso, a la frustración intelectiva de la búsqueda. Por eso es claro, para Zubiri, que tanto el agnóstico como el teísta son buscadores de Dios. En el despreocupado y el indiferente religioso, en tanto, la voluntad de fundamentalidad se modula como voluntad de vivir, de dejarse vivir, y la marcha conduce a la 'in-diferencia' entre realidad-objeto y realidad-fundamento. Y en el ateo, por fin, la voluntad de fundamentalidad se modula como voluntad de ser, una marcha racional que lleva a la facticidad del poder de lo real, en último término a la autosuficiencia de la vida ${ }^{63}$. Constatemos, aunque sólo sea al pasar, que en el artículo «En torno al problema de Dios» hay alusiones bastante despectivas a la creencia atea, en las que Zubiri no parece respetar toda la legitimidad racional y creyente de dicha opción. No se sabe si pensando en general en su propia época, o incluso en filósofos como Ortega y Heidegger, Zubiri alude allí a la existencia de personas

«[...] ejemplares por todos conceptos, pero ante las cuales surge siempre un último reparo: 'bueno, ¿y qué?...'; existencias magníficas, de espléndida figura, desligadas de todo, errantes y errabundas.... ${ }^{64}$.

Esta posible alusión a aquellos filósofos puede fundarse en que Zubiri, en el mismo texto pero un poco más adelante, acusa en la filosofía contemporánea, sobresaliente en muchos casos, una gigantesca preterición del problema de Dios, preterición que -justo por confundirse a la deidad con la divinidad- es vista como equivalente de ateísmo ${ }^{65}$.

Sea de ello lo que fuere, la consideración de la religión como fe y creencia tiene larga data en Zubiri. El curso sobre «El problema de Dios»

63 Cf. X. Zubiri (n. 20), pp. 266-294.

64 X. Zubiri (n. 28), p. 452.

65 Cf. X. Zubiri (n. 28), p. 453 n.1. 
se refiere extensamente a ella, si bien dentro de un análisis que privilegia ostensiblemente la experiencia religiosa monoteísta. En la décimo tercera sesión, por ejemplo, Zubiri dice que en la religión Dios no es sólo objeto de una idea sino término de fe. La idea de Dios tiene una concreción creyente y devocional: «Lo único que me importa subrayar es que la versión primera del hombre a Dios como religión, y no como religación, está en la articulación de esas dos dimensiones, que son, por un lado, dirigirse de tú a tú a Dios, que es el acto de la fe, y de dirigirse real y efectivamente, que es el acto de la oración». Luego, en la sesión trigésimo segunda, se añade que «este acto de voluntad de realidad es la respuesta, por lo menos sorda, pero real y auténtica, de la persona, de cada persona humana [...] a la persona creadora, a la persona que es Dios». Dicha voluntad de realidad se despliega de cuatro maneras, siguiendo la estela de las preguntas kantianas $^{66}$. La primera, ¿qué puedo saber?, da origen al ineludible problema intelectivo y personal de Dios. La segunda, ¿qué es dado esperar?, apunta a Dios como refugio y apoyo, como fuente de esperanza. La tercera, ¿qué tengo que hacer?, se dirige a la conversión, al arrepentimiento, la penitencia y el sacrificio (al que define así: «la realidad como oblación es asumida real y efectivamente por el hombre para convertirla precisamente en oblación a la divinidad: es el sacrificio»). Lo que el hombre puede saber, lo que le es dado esperar y lo que tiene que hacer son, entonces, «una idea de Dios, una esperanza en Dios y un movimiento conversivo hacia Dios». Estas tres preguntas revierten en una cuarta: ¿qué es el hombre? La respuesta religiosa a ella consiste en admitir que el hombre es, «velis nolis, una imagen formal de Dios, pura y simplemente por ser persona». Y la configuración positiva (no negativa o aversiva, perfectamente posible por cierto) de esa imagen divina consiste tanto en el esfuerzo moral del hombre como en su oración:

«La oración es, pura y simplemente, no una vaga, una mística, una mera elevación del alma a Dios; es precisamente el modo interno en que la persona se instala en ese punto crucial en que, salido de las manos de Dios, comienza a existir y está existiendo como persona absoluta. Por eso, realmente la oración representa el punto crucial y culminante de eso que es el diálogo, respuesta personal del hombre hacia Dios. La oración es vivir cuasi eternalmente» ${ }^{67}$.

66 Cf. Log.: A 25 y KrV: A 804/B 832ss.

67 Nótese que aquí la mística es acusada de vaguedad, y es identificada como una mera elevación anímica. Parejamente se expresaba ZubiRi en los años 30 y 40, cuando aludía a un «vago sentido misticoide»; vid. X. Zubiri (n. 28), p. 442. Es una prueba 
He aquí, pues, la experiencia de la fe en Dios, de la entrega humana explícita a la realidad plenaria. La realidad plenaria es la realidad absolutamente absoluta esbozada como fuente del yo y del ser. Y aunque no sea persona o vida, es probada experiencialmente como la realidad que podría ser el fondo último de la persona humana. Si la experiencia aprueba su plena absolutez, Dios será a la vez la realidad más íntima y la más lejana para el hombre. Por eso la profunda realidad de Dios podría ser hallada en el fondo del ser humano. Si así ocurre, entonces es verdad que «acudir a Dios es acudir a mi propio fondo transcendente» ${ }^{68}$, en una suerte de radical identificación que sin embargo no borra sino que subraya la diferencia entre uno y otro. El enigma del poder de lo real es, en tal caso, el misterio de Dios, en virtud del cual el hombre y Dios se vinculan de una manera razonable aunque en definitiva incomprensible. El misterio de Dios viene a ser la radical unidad del hombre con Dios mediante la transcendencia de éste en aquél. La experiencia de la fe en Dios, si es verdadera, no es sólo una experiencia (todo lo peculiar que se quiera) de Dios, sino algo más radical si cabe: el hombre es experiencia de Dios, y Dios es experiencia del hombre ${ }^{69}$. Para precisar qué es lo que Zubiri quiere decir con estas expresiones, no debe dejar de apuntarse una vez más cuán intensamente se privilegia aquí el punto de vista del monoteísmo. Pues bien: primeramente, que Dios sea experiencia del hombre significa que la propia realidad divina (personal, dice Zubiri) se da en toda su verdad real. La creación es la consecuencia de esta donación de Dios: «La creación debe considerarse como la vida misma de Dios proyectada libremente ad extra, por tanto en forma finita» $\rangle^{70}$. Dentro de ella, hay dos tipos básicos de cosas creadas. Unas son las esencias cerradas, que son todas las no humanas, y otras las abiertas o humanas. Y aunque la donación de Dios se refleja en toda esencia, es sólo en las esencias abiertas que «Dios está dándose como absoluto experiencial en forma universal» ${ }^{71}$. La donación de Dios es experiencia únicamente en el hombre, porque sólo en él puede ser metódica, racional y explícita. En esto consiste precisamente la experiencia religiosa: en que «Dios se ha dado como absoluto en la experiencia; es Dios dándose o ha-

ostensible de su oscilación a la hora de tratar con los fenómenos místicos, como comentábamos más atrás.

68 X. Zubiri (n. 20), p. 203.

69 Cf. X. Zubiri (n. 20), pp. 309-310, 325 y 348.

70 X. Zubiri (n. 20), p. 313.

71 X. Zubiri (n. 20), p. 319. 
ciéndose experienciado como absoluto» ${ }^{72}$. Por esta experiencia, el hombre hace la prueba de que Dios se le da para hacerlo persona. Y así, tiene la prueba de la realidad plenaria de Dios con toda su verdad real ${ }^{73}$. Por supuesto, esta experiencia formal de Dios tiene las tres dimensiones del ser del hombre, y es por ello muy diversa individual, social e históricamente ${ }^{74}$. Zubiri dice por esto que la fe es concreta: «Llamo concreción de la fe a los modos, matices o cualidades (poco importa el vocablo) según los cuales la fe no es sólo 'la' fe sino 'mi' fe»" ${ }^{75}$. Si es legítimo referirse a 'la' fe religiosa, lo es sólo por ser «el sentido idéntico de personas radicalmente concretas» ${ }^{76}, \mathrm{y}$ sobre cuyo diverso valor de verdad habrá que pronunciarse.

En segundo lugar, que el hombre sea experiencia de Dios significa, en palabras de Zubiri, que

«El hombre es una manera finita de ser Dios [...] El hombre es un modo, por consiguiente, experiencial de ser Dios [...] Esta experiencia es justamente la experiencia de Dios; la experiencia de lo absoluto en la medida en que es experiencia de mi ser personal» ${ }^{77}$.

El hombre es Dios finitamente porque es persona. Por esto mismo es libre: la libertad se convierte con la personeidad. Y si Dios es no sólo sostén formal de todo cuanto hay sino también raíz donante de posibilidades y forzoso impulsor de la personalidad humana, entonces es raíz e impulso de la libertad del hombre. Ya no se trata de las nociones tradicionales de 'libertad de' o de 'libertad para', sino de la idea previa de una 'libertad en': el hombre es libre en la realidad simpliciter, y por ende en su fundamento divino $^{78}$. En la experiencia de la libertad -de lo que libremente el hombre podría ser y hacer con su persona- se tiene en definitiva una experiencia de Dios ${ }^{79}$. Pero si la persona se convierte con la libertad, ésta no se convierte con Dios. Dios no es un objeto entre otros ni un estado subjetivo ni una facultad o propiedad humana, sino que es la realidad plenaria en cuya virtud el hombre es persona, es libre y aparece en el campo como

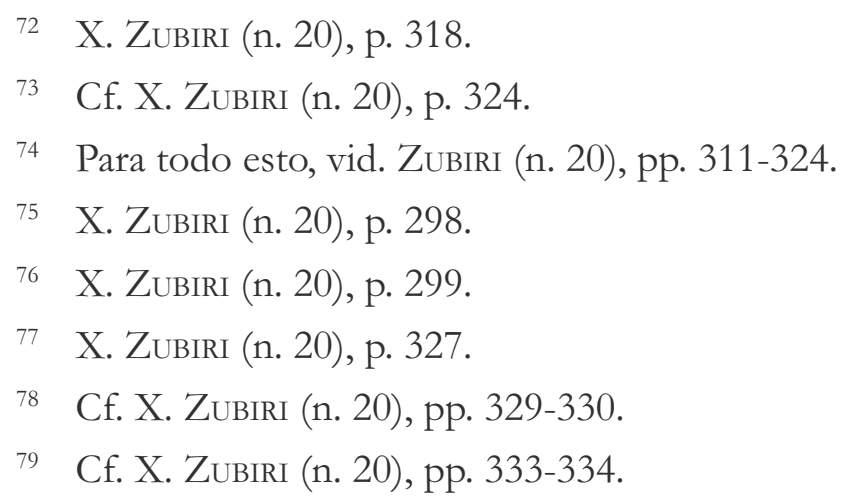


relativamente absoluto. Aun siendo relativo, en el fondo el ser humano es absoluto por virtud de Dios. El hombre es, en el campo de lo real, una realidad relativamente absoluta, porque está enfrentado con todas las cosas y dominado por el poder de lo real. La religión consiste en la experiencia de que la relativa absolutez humana está fundada en la plenitud divina, porque este ser de la transcendencia que es el hombre no es en el fondo más que una donación de Dios mismo. La figura de instauración en el ámbito de lo real de la realidad formalmente religada y atada a la voz de su conciencia se debe a que está apoyada a tergo en la realidad. Pero tanto la realidad humana como la realidad in toto están fundadas en la realidad absolutamente absoluta, que es fuente del sentido de aquélla y de ésta, del yo y del ser. Y por ser fuente del yo, Zubiri puede decir que Dios es

«lo absoluto de mi ser. Es aquello que está fundando y haciendo posible lo absoluto de mi sen» ${ }^{80}$.

La experiencia de Dios tiene, entonces, un modo radical, que es la voluntad de verdad configurada como búsqueda, esbozo y experiencia de la realidad absolutamente absoluta, en, por y desde la cual el hombre es a su vez realidad relativamente absoluta. Pero si el teísmo es verdadero, la experiencia de Dios no se restringe a los contornos de la búsqueda religiosa. La experiencia de Dios tendría en tal caso unas facetas singulares en la frustración del agnóstico y en la despreocupación del indiferente: agnosticismo y despreocupación no serían sino modos de la experiencia de Dios. Y no sólo allí. En el ateísmo también tendríamos experiencia de Dios, una experiencia encubierta, no una carencia de ella ${ }^{81}$. Si la experiencia de Dios era, a parte Dei, «Dios dándose como absoluto a la experiencia humana», a parte hominis es «la experiencia de lo absoluto en la constitución de mi persona ${ }^{82}$, plena en el creyente, encubierta, frustrada o despreocupada (en suma, desconocida) en el que no lo es. Tal plenitud de la experiencia religiosa no alcanza sólo a su develación cognoscitiva sino ante todo a la íntegra existencia humana. Zubiri subraya por eso que la religión es una experiencia de plenitud, no de indigencia: la manifestación de Dios se dirige a la plenitud de la existencia más que a la indigencia del vivir. El

\footnotetext{
80 X. Zubiri (n. 20), p. 328.

81 Cf. X. Zubiri (n. 20), pp. 334-344.

82 X. Zubiri (n. 20), p. 344.
} 
hombre va a Dios y está en él sobre todo «en la plenitud misma de la vida, a saber: en hacerse persona» ${ }^{83}$.

Así, pues, la fe específicamente religiosa es conformación del yo en entrega confiada a la divinidad que fundamenta todas las cosas. La religión es, por parte del hombre, experiencia del hombre en Dios y de Dios en el hombre. Puede ser también, aunque no siempre, entrega humana posibilitada por la previa donación de la persona o de la vida divina. A la vez, la opción religiosa más racional se plasma en una voluntad de fundamentalidad para la cual Dios es realidad plenaria, no ociosa sino fundamentante. Dios es fundamentante cuando la razón religiosa es racional y reconoce en la realidad plenaria el fundamento del poder de lo real como poder último, posibilitante e impelente. La vía de la religación abre distintas rutas para probar la realidad divina. Probarla sobre todo en el sentido de tener experiencia de ella, aunque también ensayando la demostración de que tal realidad tiene que tener ciertas propiedades como fundamento del yo y del ser, y que, así concebida, tiene que existir. La prueba, por ende, no es una pura demostración. La razón religiosa ha de ser no sólo racional sino también razonable. Esto implica que la fe religiosa, la voluntad teísta de fundamentalidad, consiste en:

«hacer pasar a mi yo aquello que la razón me haya probado ser la realidad-fundamento. Es la actitud de entregarse al fundamento que la razón descubra» ${ }^{84}$.

La fe no excluye el conocimiento; más bien, es un momento del método de la razón y del conocimiento. Si dentro del ámbito de la fe religiosa cabe una razón más o menos racional, la fe religiosa misma es ante todo razonable, en la medida en que es y no puede dejar de ser «la congruencia querida con lo racional $\rangle^{85}$. Zubiri dice todavía algo más: que lo razonable es más que lo estrictamente racional justo porque incluye este momento de volición y entrega, o sea, de experiencia y fe. La llegada a la fe religiosa es conocimiento porque tiene un apoyo racional, aunque es más que estricta racionalidad probadora y demostrativa: es la razonabilidad de la opción creyente religiosa tomada en y por sí misma. Por lo que tiene de

X. ZuBiri (n. 20), p. 344.

84 X. Zubiri (n. 20), p. 263.

85 X. ZuBiri (n. 20), p. 263. En la sesión trigésimo tercera del curso sobre «El problema de Dios», dice Zubiri que «la razón está inserta dentro del dominio de la fe», no como racionalidad estricta y demostrativa, sino como ámbito que es razonable: «Razonable es la dimensión intelectual de la fe». 
razonable, la fe religiosa es una opción basada en razones acerca del poder de lo real y de los sentidos construidos a partir de él. Dentro de esta experiencia razonable, la posible ociosidad de Dios no es más que una disociación entre el conocimiento y la fe o, mejor, es un conocimiento religioso racionalmente insuficiente. En cambio, todo lo que en la religión aspira a ser demostrativo, aunque importante y legítimo, es siempre algo derivado. La prueba de Dios es, para Zubiri, primeramente un momento del método racional, y sólo secundariamente puede adoptar la forma de una demostración ceñida a la disciplina lógica. Zubiri nunca excluye la posibilidad de elaborar argumentaciones lógicamente válidas acerca del concepto o de la existencia de Dios, a condición de reconocer que todas ellas se basan en la estructura metódica de la razón humana según la cual la experiencia es un momento indispensable. Las argumentaciones racionales estrictas son unos razonamientos que no se identifican con el método de la razón, sino que han de someterse al tribunal de la lógica. En tanto que razonamientos lógicos, estas argumentaciones son una parte -no el todo, ni siquiera la parte más importante- del proceso intelectual desencadenado a propósito de Dios. Y, aunque sean elaboradas siguiendo las reglas de la inferencia válida, no pueden pretender conclusividad definitiva respecto de la existencia de Dios y de sus propiedades, puesto que la realidad de Dios es plenaria y por ende infinita e irrepresentable, y su noción, internamente inestable y lingüísticamente analógica. 
Resumen: se expone en este trabajo una posible reconstrucción de la estructura de la razón religiosa al hilo de la fenomenología o analítica de la inteligencia de Zubiri. Así, la modalidad intelectiva racional es presentada a la luz de su particular configuración religiosa o teísta. La razón, en efecto, viene a ser una profundización del logos religioso y, por lo mismo, de la interpretación específicamente teísta del poder de lo real que, según Zubiri, religa a la existencia humana y a todas las cosas. Dios es, entonces, la realidad plenaria que se esboza y experiencia por conformación de la vida humana y - a veces- por compenetración con su realidad personal o vital, y en todo caso como realidad fundamental digna de fe y confianza.

Palabras clave: religión, Dios, teísmo, racionalidad, fenomenología, Zubiri, método, experiencia.

Abstract. This paper discussed in a possible reconstruction on the structure of the religious reason in a row of the Zubiri's phenomenology or analytical of the intelligence. Thus, the mode rational of intelligence is presented in the light of their particular religious or theistic configuration. The reason, indeed, amounts to a deepening of religious logos and, therefore, of specifically theistic interpretation on the power of reality, that, according to Zubiri, reconnects to human existence and all things. God then is the summum reality outlined and experienced shaping human life and, at times, by bonding with their personal reality or life, and in any case as fundamental reality of faith and trust worthy.

Key words: religion, God, theism, rationality, phenomenology, Zubiri, method, experience. 